\title{
POTENTIAL OF OZONE AND HYDROXYL RADICALS TO DEGRADE EMERGING ORGANIC CONTAMINANTS
}

\author{
A Thesis \\ presented to \\ the Faculty of California Polytechnic State University, \\ San Luis Obispo \\ In Partial Fulfillment \\ of the Requirements for the Degree \\ Master of Science in Civil and Environmental Engineering \\ by \\ Lisa Elaine Vance \\ October 2017
}


(C) 2017

Lisa Elaine Vance

ALL RIGHTS RESERVED 


\section{COMMITTEE MEMBERSHIP}

TITLE:

Potential of Ozone and Hydroxyl Radicals to Degrade Emerging Organic Contaminants
AUTHOR:
Lisa Elaine Vance

DATE SUBMITTED: October 2017

COMMITTEE CHAIR: $\quad$ Rebekah Oulton, Ph.D., P.E.

Assistant Professor of Civil and Environmental

Engineering

COMMITTEE MEMBER: Tryg Lundquist, Ph.D., P.E.

Professor of Civil and Environmental Engineering

COMMITTEE MEMBER: Amro El Badawy, Ph.D.

Research Scholar and Lecturer 


\begin{abstract}
Potential of Ozone and Hydroxyl Radicals to Degrade Emerging Organic Contaminants
\end{abstract}

\author{
Lisa Elaine Vance
}

Advanced water treatment processes are necessary for the treatment of emerging organic contaminants. Traditional treatment processes do not filter or treat these contaminants, causing humans and animals to come into contact and ingest them, potentiallyboth causing illness. Advanced oxidation processes (AOPs) are a good alternative method, but current AOPs are cost and time intensive.

Previous research on ozone and hydroxyl radicals leads to the conclusionindicates that they might be a viableal option for advanced water treatment processes.

To test the effects of ozone and hydroxyl radicals on the destruction of algae, ozonated phosphate buffer was mixed with Anabaena and modified BG11 culture media and placed in a culturing apparatus to regrow the destructed Anabaena. The biomass density was measured via the optical density for five days and compared to controls. Exposure to ozone killed most of the algae in each batch, as expected. The higher the concentration of ozone, the higher amount of algal destruction. The Ozone Plus generator was more powerful at initial algal destruction than the Standard ozone generator, as indicated by the comparison between the results at $2 \mathrm{ppm}$ ozone concentration.

To test the effects of ozone and hydroxyl radicals on the treatment of carbamazepine (CMZ) and phenytoin (PHT) in controlled water systems, ozonated phosphate buffer was mixed with $2.0 \mathrm{mM}$ carbamazepine or $2.0 \mathrm{mM}$ phenytoin solution. The dissolved organic carbon was measured through a total organic carbon (TOC) analyzer. to determine degradation of organic compounds after exposure to ozone. With the same goal in mind, other experiments were performed using oOzonated carbon nanotubes (CNTs) were used to treat carbamazepine $\mathrm{CMZ}$ and phenytoin PHT in a series of increasingly complex water systems. To test the effects of ozonated carbon nanotubes on the treatment of carbamazepine and phenytoin, mixtures of $5.0 \mathrm{mM}$ carbamazepine or phenytoin and tertbutonal were treated with ozonated phosphate buffer or treated effluent wastewater and $10 \mathrm{ppm}$ or $20 \mathrm{ppm}$ carbon nanotube solid loading. A high-performance liquid chromatography analyzer was used to measure the treated carbamazepine and phenytoin in the mixtures and compared to controls.

The TOC test was used to determine the pharmaceutical destruction to ozone dose relationship was expected to be linear, but these results were inconclusive due to the maximum reduction of less than $10 \%$ for any level of ozone. In the simple media tests, $\mathrm{CMZ}$ was seemed to be completely destroyed when exposed to ozone, but a suspected 
breakdown product was measured. PHT had the most degradation with a CNT loading of $10 \mathrm{ppm}$ and no ozone. This test suggests sorption had a greater effect on the pharmaceuticals than ozone or $\cdot \mathrm{OH}$ did. In more complex systems involving a mixture of the two pharmaceuticals in both a phosphate buffer, PHT with a CNT loading of $10 \mathrm{ppm}$ had a degradation of $14 \%$ and $4 \%$ for a CNT loading of $20 \mathrm{ppm}$. The low degradation rate is most likely due to ozone reacting with other organic matter in the reactor and not the PHT. This was the same in theIn more complex systems involving a mixture of the two pharmaceuticals in both a phosphate buffer and a wastewater effluent system PHT with a CNT loading of $10 \mathrm{ppm}$ had a degradation of $12 \%$ and $6 \%$ for a CNT loading of $20 \mathrm{ppm}$. The low degradation rate is most likely due to ozone reacting with other organic matter in the reactor and not the PHT.

In all three Chapters, the ozone and hydroxyl radicals showed moderate reduction in emerging organic contaminants. These results suggest that ozone and hydroxyl radicals generated from ozonated CNTs have potential to be an effective alternative to current AOPs, and that further study to refine the process is merited. 


\section{ACKNOWLEDGMENTS}

I would like to express my sincere appreciation to the following people:

Dr. Rebekah Oulton for your support and advice in both my undergraduate and graduate years, for allowing me to continue and build on your research, and for believing in me as a student and as an engineer.

Dr. Tryg Lundquist and for organizing funding of this project and for your time helping in experimental design.

Dr. Amro El Badawy for your time, support, and guidance over the past year.

Emily Miller, Ruby Lang, and Lizzie Wiley for your time helping me with research, commitment to the project, and most importantly for making lab so enjoyable.

All undergraduates who assisted, but were not mentioned here.

Russell Davis and Robert Stone for supporting my research.

Courtney Whiting and family for the unending support you gave me during my time at Cal Poly.

And to my loving and caring parents for being my support system over these past twentyone years of education - especially as the stress increased in college. 


\section{TABLE OF CONTENTS}

Page

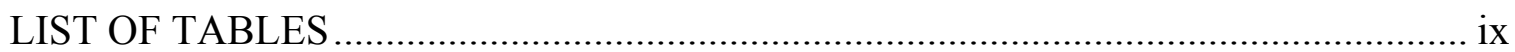

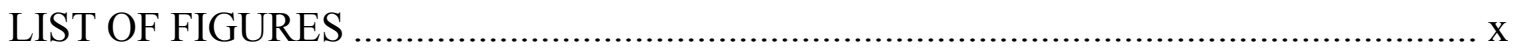

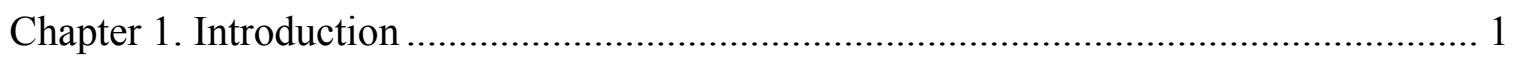

Chapter 2. Ozone Effects on Anabaena Algae …………............................................. 5

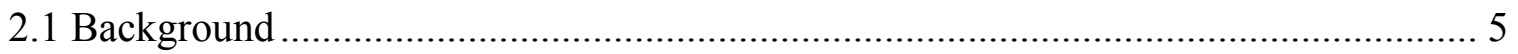

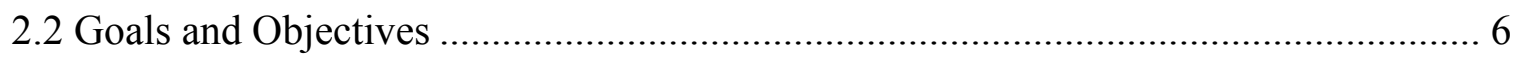

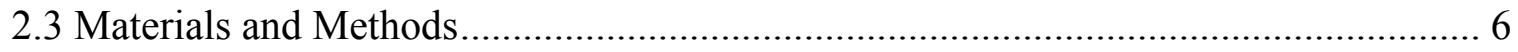

2.3.1 Algal Cell Build Up Growth Procedure ................................................................. 7

2.3.2 Ozone Stock Solution Preparation ................................................................... 8

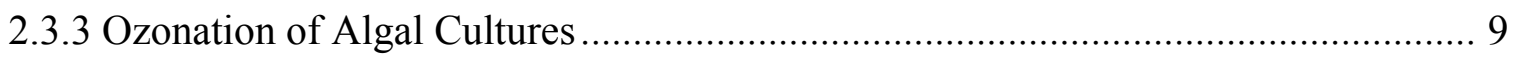

2.3.4 Post Ozonation Anabaena Growth Analysis............................................................ 12

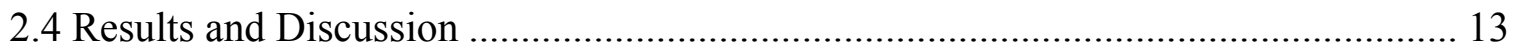

Chapter 3. Ozone Effects on Organic Pharmaceuticals ................................................ 17

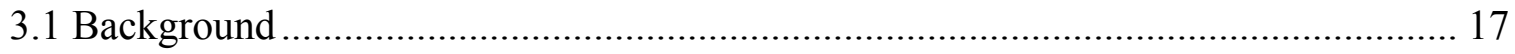

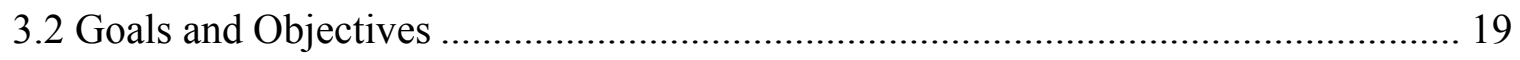

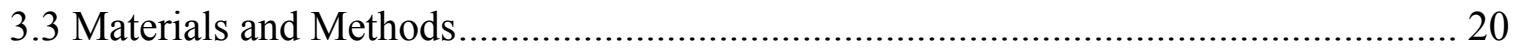

3.3.1 Phase 1: Impact of Varying Degrees of Ozone on Pharmaceuticals ....................... 20

3.3.2 Phase 2: Ozonated CNT Exposure on Pharmaceuticals in Simple Model Water

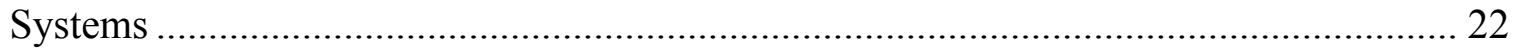

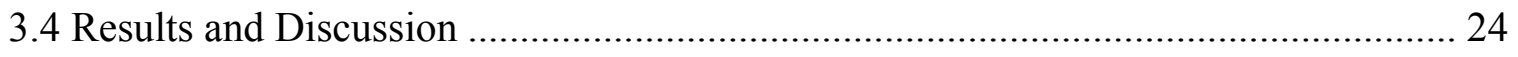

Chapter 4. Ozone and AOP Effects on Complex Water Systems..................................... 30 
4.1 Background

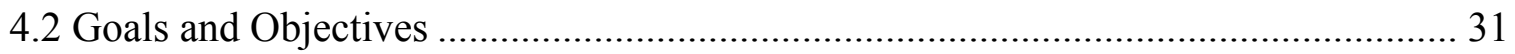

4.2.1 Simple Model System with Pharmaceutical Mixture Procedure ........................... 31

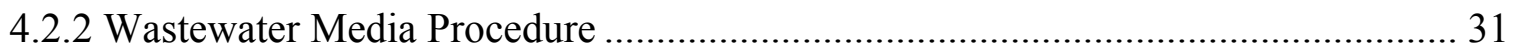

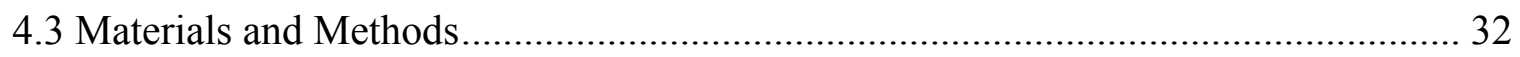

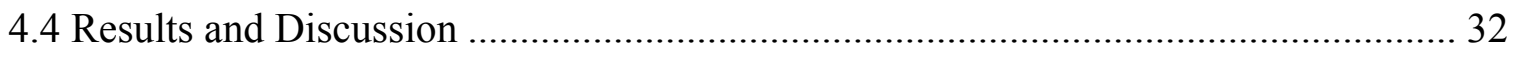

4.4.1 Phase 1: Simple Model Water System with MIX ............................................... 32

4.4.2 Phase 2: Wastewater Media ................................................................................ 34

Chapter 5. Conclusions and Future Work ............................................................. 36

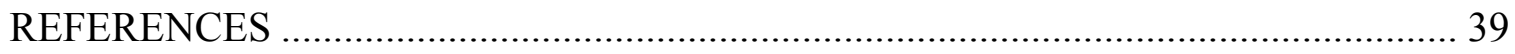

APPENDICES

Appendix A: Optical Density Measurements for Algal Destruction....................41

Appendix B: Replication of p-CBA Tests From Previous Studies (Oulton, 2014)........42

Appendix C: The results of CMZ in the MIX tests and wastewater tests................43 


\section{LIST OF TABLES}

Table

Page

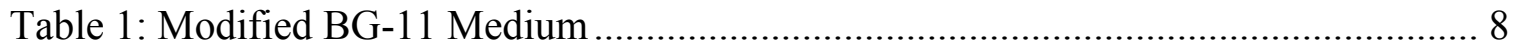

Table 2: Targets and Specific Volumes Used in Experiment ..................................... 10

Table 3: TOC Vial Recipe for Standard Ozone Generator ............................................ 21

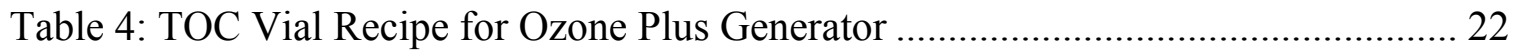

Table A: The Five-Day Optical Density Measurements for the Control, Ozone Plus 3

ppm, Standard 2 ppm, and Ozone Plus 2 ppm Concentrations................................... 41 


\section{LIST OF FIGURES}

$\begin{array}{lll}\text { Figure } & \text { Page }\end{array}$

Figure 1: Diagram (left) and photo (right) of assembled 750-mL square bottle for custom culturing apparatus. Diagram of square bottle (A) includes: (B) rubber stopper, (C) Pasteur pipette, (D) cotton plug, (E) disk filter, (F) flexible tubing,

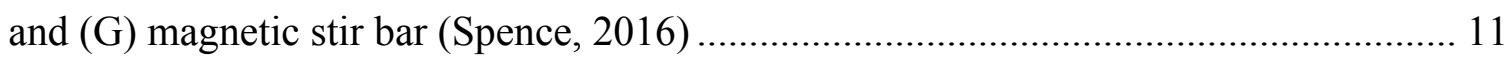

Figure 2: Top view of the custom culturing apparatus (Spence, 2016) ........................... 12 Figure 3: Visual results of ozonation of algal toxins showing (from left to right) the control, Standard generator at 2 ppm ozone, Ozone Plus at 2 ppm ozone, and Ozone Plus at 3 ppm ozone, immediately after ozone treatment

Figure 4: Optical Density results of the four tests: Control, Ozone Plus at 3 ppm ozone, Standard generator at 2 ppm ozone, and Ozone Plus at 2 ppm ozone .......................... 15

Figure 5: Molecular structure of both phenytoin and carbamazepine (Rezaei, 2014).....17 Figure 6: Comparison of concentration of ozone verses concentration of non-portable organic carbon (Phase 1) with three trials each ...................................................... 24 Figure 7: Degradation of CMZ in simple model water systems all trials with an initial

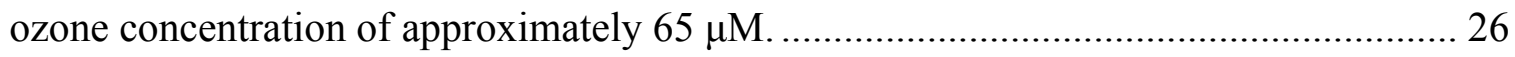

Figure 8: Degradation of phenytoin PHT in the controlled media tests with all trials

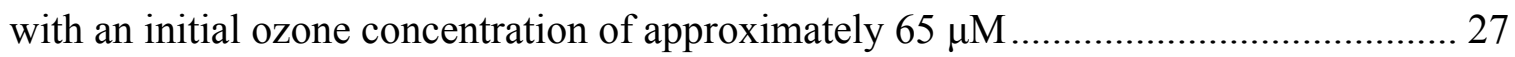

Figure 9: Degradation of PHT in the MIX tests with comparison to controls................. 33

Figure 10: Degradation of PHT in the WW tests with comparison to control ................ 34 Figure 11: Comparison of degradation of PHT with ozone and $10 \mathrm{mg} / \mathrm{L} \mathrm{CNT}$ solid loading in simple media, MIX media, and WW media ............................................ 35 
Figure A: p-CBA Tests and Ozone Controls Showing Correct

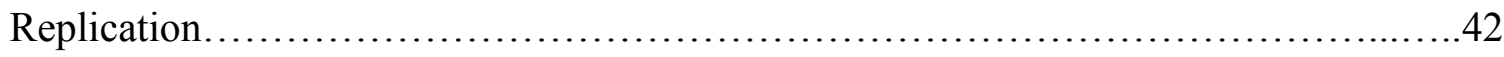

Figure B: Degradation of CMZ in the mixed media tests with comparison to

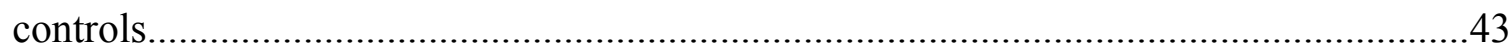

Figure C: Degradation of CMZ in the wastewater media tests with comparison

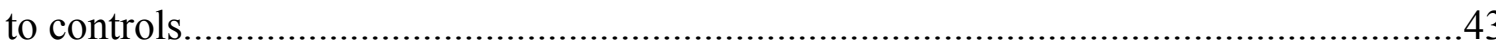




\section{Chapter 1. Introduction}

This study shows how effectively ozone facilitates breakdown of specific organic pollutants in water. It includes three phases: ozone breakdown of algae in simple model water systems (Chapter Two); ozone and ozone-based advanced oxidation processes (AOPs) breakdown of pharmaceuticals in simple model water systems (Chapter Three), and ozone and ozone-based AOP breakdown of pharmaceuticals in complex water systems (Chapter Four).

Only 3\% of the Earth's freshwater is available for use and even less is available to consume, and, of this $3 \%, 69 \%$ is stored in ice caps and glaciers, $30 \%$ comprises groundwater, and $0.3 \%$ makes up surface water, according to Lippelt (2015). She also notes that many available sources are becoming polluted or drying up, with currently, 700 million people worldwide affected. She predicts that this number is likely to double in the next five years, and populations that do have access to fresh water are likely overusing it.

In addition to the challenge of world water scarcity, most groundwater and surface water is becoming increasingly contaminated, according to Fawell (2003). He mentions that natural contaminants are present in all bodies of water and include: inorganics from rocks and geological debris, microorganisms, and chemicals. Also that anthropogenic contaminants include: industrial runoff, by-products of water and sewage treatment, agricultural waste, chemical spills, and eutrophication. He goes on to say that all of these contaminants pose concern; depending on the contaminant, water can become non- 
potable, cause health problems for animals and humans, and negatively impact the environment.

While previous water quality research has mainly focused on the more common contaminants discussed above, such as metals, industrial chemicals, bacteria, and priority pollutants, improved analytical technology has revealed an array of organic contaminants that have not previously been considered (Pal, 2014). These environmental contaminants range in concentration from $1 \mathrm{ng} / \mathrm{L}-1 \mu \mathrm{g} / \mathrm{L}$ and include: hormones, antibiotics, surfactants, endocrine disruptors, human and veterinary pharmaceuticals, X-ray contrast media, pesticides and metabolites, disinfection-by-products, algal toxins, and taste-andodor compounds (Pal, 2014). The main sources of entry of such pollutants into surface and groundwater include: municipal wastewater, hospitals, construction sites, landscaping, transportation, industrial farming, and manufacturing (Pal, 2014). Some less common sources of entry are leaking pipelines, landfills, and improperly disposed wastes (Pal, 2014).

Ongoing studies suggest many of these emerging contaminants do not get effectively removed in conventional water or wastewater treatment plants, and humans and animals are consuming them via ingestion of water or animal products (Oulton, 2010; Pal, 2014). Humans and animals are also affected by these contaminants via direct contact with contaminated waters. Since these emerging contaminants are linked to a variety of ecological issues, effective methods to break them down are needed (Pal, 2014). Thus, alternative water treatment methods to conventional water treatment methods are needed. 
AOPs are an alternative to traditional wastewater treatment methods in the treatment of organic pollutants (Ikehata, 2006). Some AOPs may involve ozone, hydrogen peroxide, transition metals, metal oxides, and ultraviolet-visible radiation (Ikehata, 2006). Through chemical reaction between two or more of these components, AOPs generate hydroxyl radicals $(\cdot \mathrm{OH})$, which then breakdown the organic pollutants (Ikehata, 2006). AOPs are a good alternative to conventional treatment for treatment of organics, specifically pharmaceuticals, in water due to their low energy and material use (Ikehata, 2006). However, AOPs are extremely cost and time intensive to treat the low levels of pharmaceuticals in water (Abdelmelek, 2011).

Ozone, a common factor in AOPs, has been used for the treatment of potable water and wastewater since 1886 (Loeb, 2012). Ozone can be used to target odor, trihalomethanes, color, cryptosporidium, pesticides, magnesium, iron, and taste (Loeb, 2012). Wastewater treated with ozone can be used for landscaping, lavatory flushing, sprinkling systems, recreational, and maintenance purposes, as well as industrial purposes (Loeb, 2012). Ozone for wastewater treatment disinfection is a common practice in the United States, but chlorine or ultraviolet radiation are generally more cost effective treatments (Loeb, 2012). However, ozone is a stronger oxidant and may be more effective against resistant contaminants because it reacts well with double bonds, non-protonated amines, and activated aromatic systems (Von Gunten, 2003).

Ozone is an unstable chemical, thus when using it there are always two chemical species involved: ozone and hydroxyl radicals (Von Gunten, 2003). The breakdown process of 
ozone occurs naturally in water (Von Gunten, 2003). Ozone is a selective oxidant, while - $\mathrm{OH}$ are the strongest oxidants in water, which results in quick reactions with dissolved compounds (Von Gunten, 2003). This research explores the potential of ozone and $\cdot \mathrm{OH}$ to degrade emerging organic contaminants. 


\section{Chapter 2. Ozone Effects on Anabaena Algae}

\subsection{Background}

Algae cyanobacteria can grow excessively under stable conditions and high nutrient levels, which can cause problems with taste, odor, coagulation processes, and clog filters during water treatment (Von Gunten, 2003; Plummer, 1998). Furthermore, the presence of algae in lakes and reservoirs interferes with the treatment of the water due to the disinfection byproducts that are created when algae is treated with chlorine (Plummer, 1998). These toxins can also produce microcystins, nodularins, saxitoxins, anatoxins, and cylindrospermopsin (Von Gunten, 2003). Thus, are a hazard for drinking water safety, and if consumed can cause liver damage, cancer of the liver, and neurotoxicity (Von Gunten, 2003).

In a 2008 study, ozone had a high destruction rate on Microcystis aruginosa algal cells and its growth inhibition with an ozone dose of 3 ppm (Miao, 2009). The destruction of the algae is thought to happen by the ozone attacking the cell membrane and then the cell itself (Miao, 2009).

Two ozone generators were used to test the effects of ozone on algae: a standard ozone generator and an ozone generator thought to produce tetraoxygen as well as ozone. ClearWater Tech's CD1500P used the corona discharge method and ran on 99.9\% pure oxygen from Praxair. This ozone generator produced a dissolved ozone concentration between 75-100 $\mu \mathrm{M}$ after 15 minutes of ozonation. The Ozone Plus O4 Generator used Ozone Plus Water Systems technology to produce ozone and possibly tetraozone, running 
on ambient air. Ozone Plus states that their technology "produces $450 \%$ longer lasting oxygen allotrope half-life than any other ozone generator in the global marketplace" (Ozone, 2016). This ozone generator produced a dissolved ozone concentration between $300-400 \mu \mathrm{M}$ after 15 minutes of ozonation.

\subsection{Goals and Objectives}

Algae interfere with conventional water treatment methods and create toxic by-products, which are hazardous to humans and the environment. This chapter will build off other studies showing ozone has had a positive effect at the destruction of algae to better understand the difference varying degrees of ozone and ozone production method have on algae. The specific goals of this study are to:

1. Determine the extent of algal destruction associated with degrees of exposure to ozone.

2. Determine if the ozone production method affects the rate of algal destruction.

\subsection{Materials and Methods}

To determine ozone effects on algae, algae was cultured to build up the cell count, exposed to varying degrees of ozone, and cultured after ozone exposure to test if growth was inhibited. 


\subsubsection{Algal Cell Build Up Growth Procedure}

Pure Anabaena algal stock cultures (California Polytechnic State University) were mixed with BG-11 Medium (Table 1) at a volumetric ratio of 2:3 for optimum growth conditions, and placed in a custom light rack that provided ideal light, temperature, and carbon dioxide conditions. Optical density (OD) measurements were taken once a day to determine when the culture reached late stage lag phase. This was done by pipetting 2 $\mathrm{mL}$ of uniformly dispersed culture into a cuvette with a $1 \mathrm{~cm}$ path length and taking absorbance measurements at $750 \mathrm{~nm}$ on a Unico S-1205 spectrophotometer. The algae culturing process took five days. 
Table 1: Modified BG-11 Medium

\begin{tabular}{ccc}
\hline Stock Solution & $\begin{array}{c}\text { Concentration } \\
(\mathbf{g} / \mathbf{L})\end{array}$ & $\begin{array}{c}\text { Volume } \\
(\mathbf{m L})\end{array}$ \\
\hline $\begin{array}{c}\text { Iron Ammonium } \\
\text { Citrate Solution }\end{array}$ & 6.0 & 3.0 \\
\hline Sodium Nitrate & 150.0 & 10.0 \\
\hline Dipotassium & 31.0 & 3.0 \\
\hline Phosphate & & \\
\hline
\end{tabular}

Magnesium Sulfate

Heptahydrate
75.0
1.0

Calcium Chloride

\begin{tabular}{ccc} 
Dihydrate & 147.0 & 1.0 \\
\hline Sodium Carbonate & 106.0 & 1.0 \\
\hline EDTA Disodium & & 1.0 \\
Salt & 0.85 & 1.0 \\
\hline
\end{tabular}

\subsubsection{Ozone Stock Solution Preparation}

Gas from an ozone generator was bubbled into an Erlenmeyer flask holding $100 \mathrm{~mL}$ of $85 \% 5.0 \mathrm{mM}$ phosphate buffer created with potassium phosphate monobasic (Fisher Scientific) and $\mathrm{pH}$ adjusted to 7.0. This flask was placed in an ice bath to keep the temperature of the ozone solution at $4^{\circ} \mathrm{C}$. After 15 minutes of bubbling, the ozone concentrations were determined to be stable from previous tests. Dissolved ozone concentrations were measured using the Thermo Scientific Genesys 10S UV-Vis 
spectrophotometer $\left(\varepsilon_{258}=2900 \mathrm{~L} / \mathrm{mol} \mathrm{cm}\right)$ (Bader, 1981). The ozone concentrations varied between 75-400 $\mu \mathrm{M}$ depending on ozone generator used.

\subsubsection{Ozonation of Algal Cultures}

The target VSS value for this experiment was 40 ppm, which was VSS value from previous studies (Miao, 2009). To obtain this, the target VSS/ozone ratio was either 20 or 13.5 VSS/ozone based on the ozone generator since the Ozone Plus generator was able to reach higher ozone concentrations. Table 2 shows the added amounts of algal cultures and BG-11 Medium (algae solution), ozonated phosphate buffer, and non-ozonated phosphate buffer created with potassium phosphate monobasic (Fisher Scientific) to obtain target values. The solutions were combined into $2 \mathrm{~L}$ reagent bottles, shaken vigorously, and split into $750 \mathrm{~mL}$ square bottle (Figure 1). The non-ozonated phosphate buffer was used as a control. The stock solutions were added in the order specified in Table 2 to deionized water. 
Table 2: Targets and Specific Volumes Used in Experiment

\begin{tabular}{|c|c|c|c|c|c|c|}
\hline $\begin{array}{c}\text { Ozone } \\
\text { Generator }\end{array}$ & $\begin{array}{c}\text { Target } \\
{\text { VSS } / 0_{3}} \\
\text { ratio }\end{array}$ & $\begin{array}{c}\text { VSS } \\
\text { Target } \\
\text { (ppm) }\end{array}$ & $\begin{array}{c}\mathrm{O}_{3} \\
\text { Target } \\
\text { (ppm) }\end{array}$ & $\begin{array}{c}\text { Volume } \\
\text { Ozonated } \\
\text { Buffer } \\
\text { (L) }\end{array}$ & $\begin{array}{c}\text { Algae } \\
\text { Solution } \\
\text { (L) }\end{array}$ & $\begin{array}{c}85 \% \\
\text { Phosphate } \\
\text { Buffer } \\
\text { (L) }\end{array}$ \\
\hline Ozone Plus & 20 & 40 & 2 & 0.375 & 0.162 & 0.963 \\
\hline Ozone Plus & 13.5 & 40 & 3 & 0.556 & 0.162 & 0.782 \\
\hline Standard & 20 & 40 & 2 & 0.6 & 0.162 & 0.738 \\
\hline
\end{tabular}




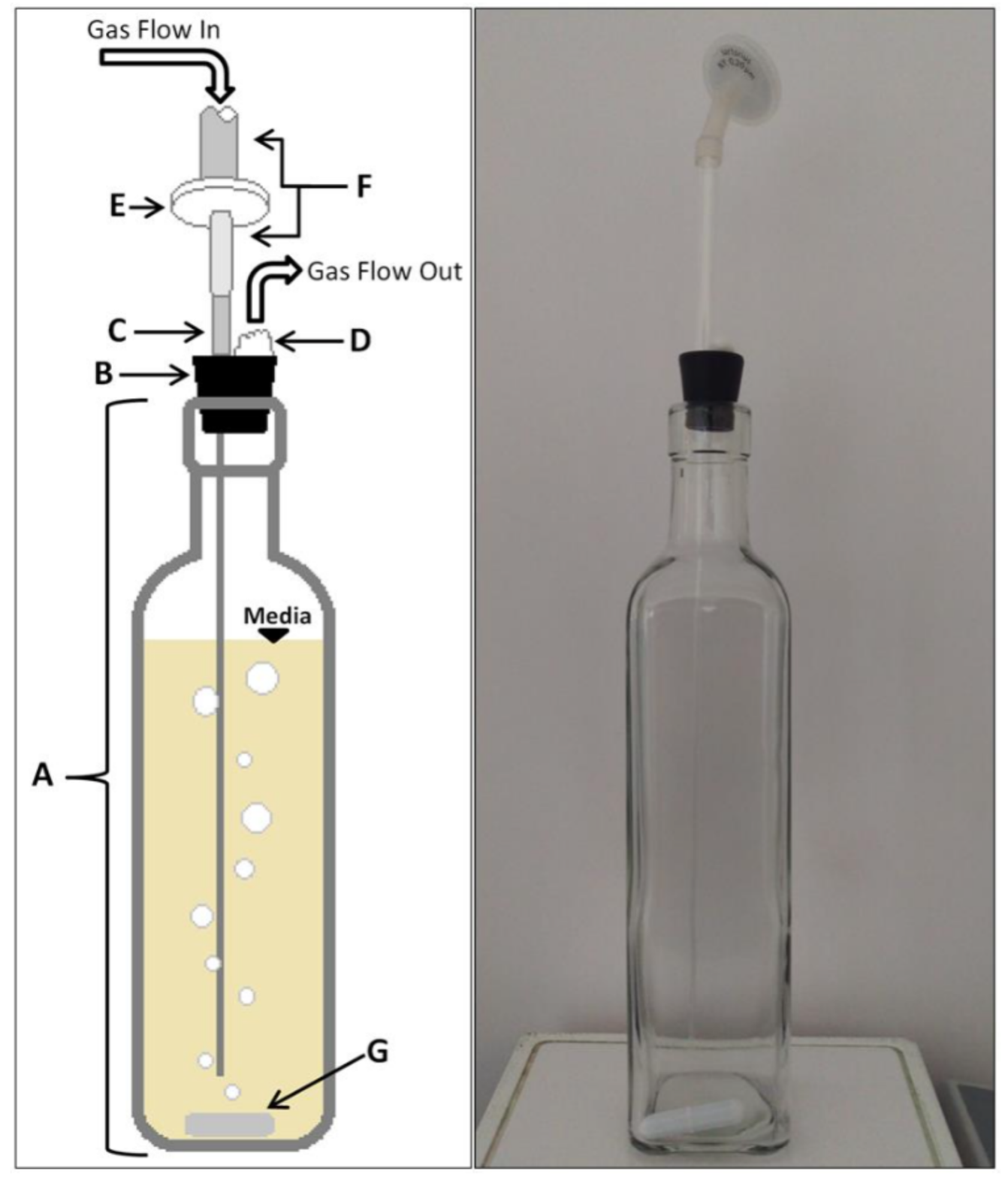

Figure 1: Diagram (left) and photo (right) of assembled 750-mL square bottle for custom culturing apparatus. Diagram of square bottle (A) includes: (B) rubber stopper, $(\mathrm{C})$ Pasteur pipette, (D) cotton plug, (E) disk filter, (F) flexible tubing, and (G) magnetic stir bar (Spence, 2016). 


\subsubsection{Post Ozonation Anabaena Growth Analysis}

The 12, $750 \mathrm{~mL}$ square bottles were placed on a custom culturing apparatus (Figure 2).

This culturing apparatus is made of two ten-station magnetic stir plates placed in a water bath aquarium make up the base of the apparatus. The lights (two fluorescent lamps on each length of the apparatus) were on a 12 hour-on and 12 hour-off cycle. Two pumps were used to keep the water temperature steady throughout the apparatus. A black plastic film was used as a center baffle between the bottles to ensure they were getting the same amount of light. Air and carbon dioxide were constantly sparging in the bottles to keep the $\mathrm{pH}$ levels of each bottle around 7.0. The temperature was held constant at $22-24^{\circ} \mathrm{C}$ and controlled through water circulator fans placed on opposite ends of the tank.

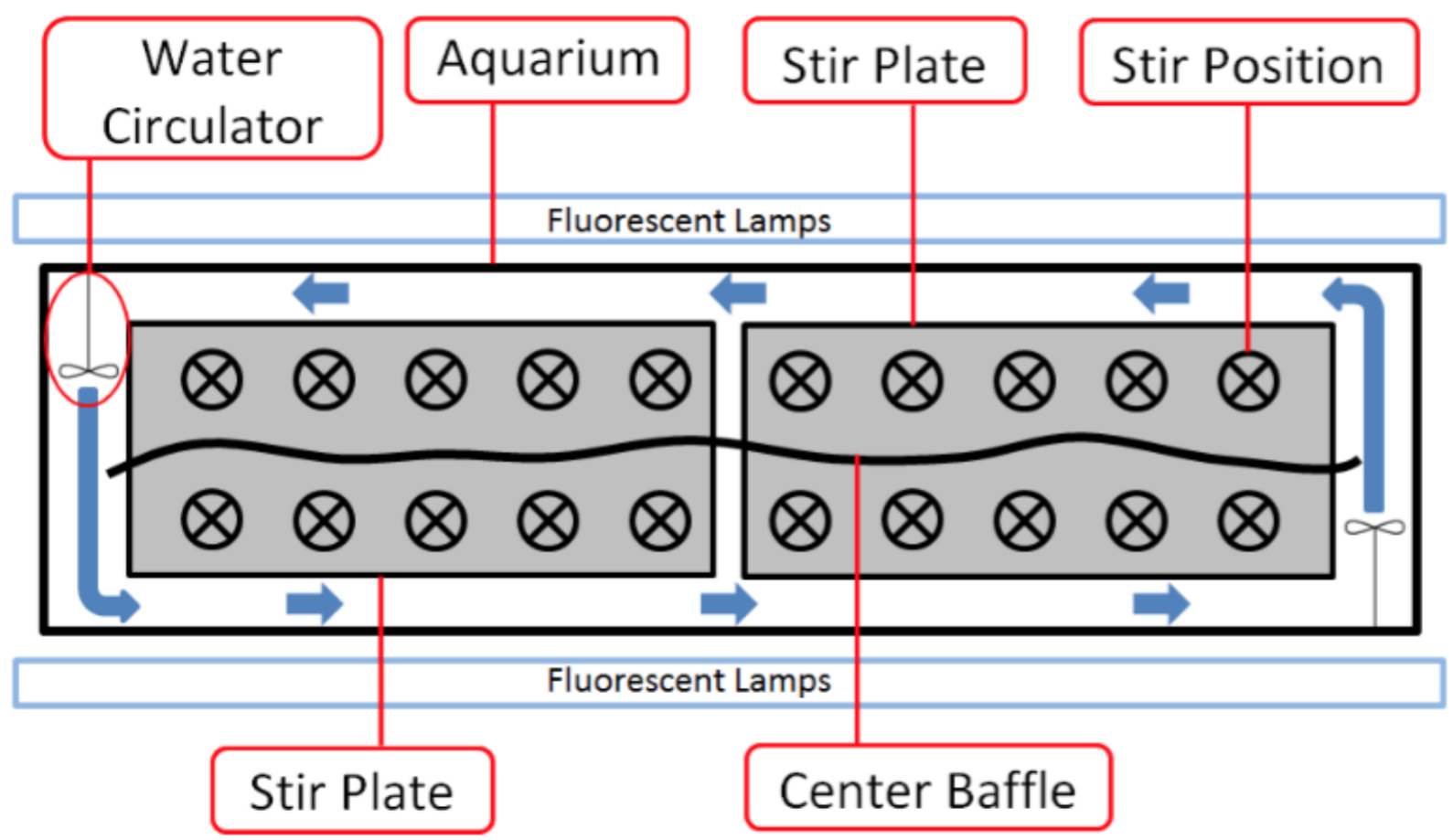

Figure 2: Top view of the custom culturing apparatus (Spence, 2016). 
Optical density measurements of the anabaena culture in the custom light rack were taken by pipetting $2 \mathrm{~mL}$ of uniformly dispersed culture into a cuvette with a $1 \mathrm{~cm}$ path length and taking absorbance measurements at $750 \mathrm{~nm}$ on a Unico S-1205 spectrophotometer. The OD measurements were taken immediately after ozonation and every 24 hours for five days while the cultures were in the culturing apparatus.

In addition, $\mathrm{pH}$ measurements were taken every 24 hours for five days with an Oakton $\mathrm{pH} / \mathrm{mV} /{ }^{\circ} \mathrm{C}$ meter 11 series. If the $\mathrm{pH}$ levels of each bottle were not between a $\mathrm{pH}$ of 6-8, the air and carbon dioxide levels were changed to obtain proper growth conditions.

\subsection{Results and Discussion}

Before the reactor bottles were placed into the culturing apparatus, a visual inspection was made on the immediate degradation of the algae (Figure 3). 


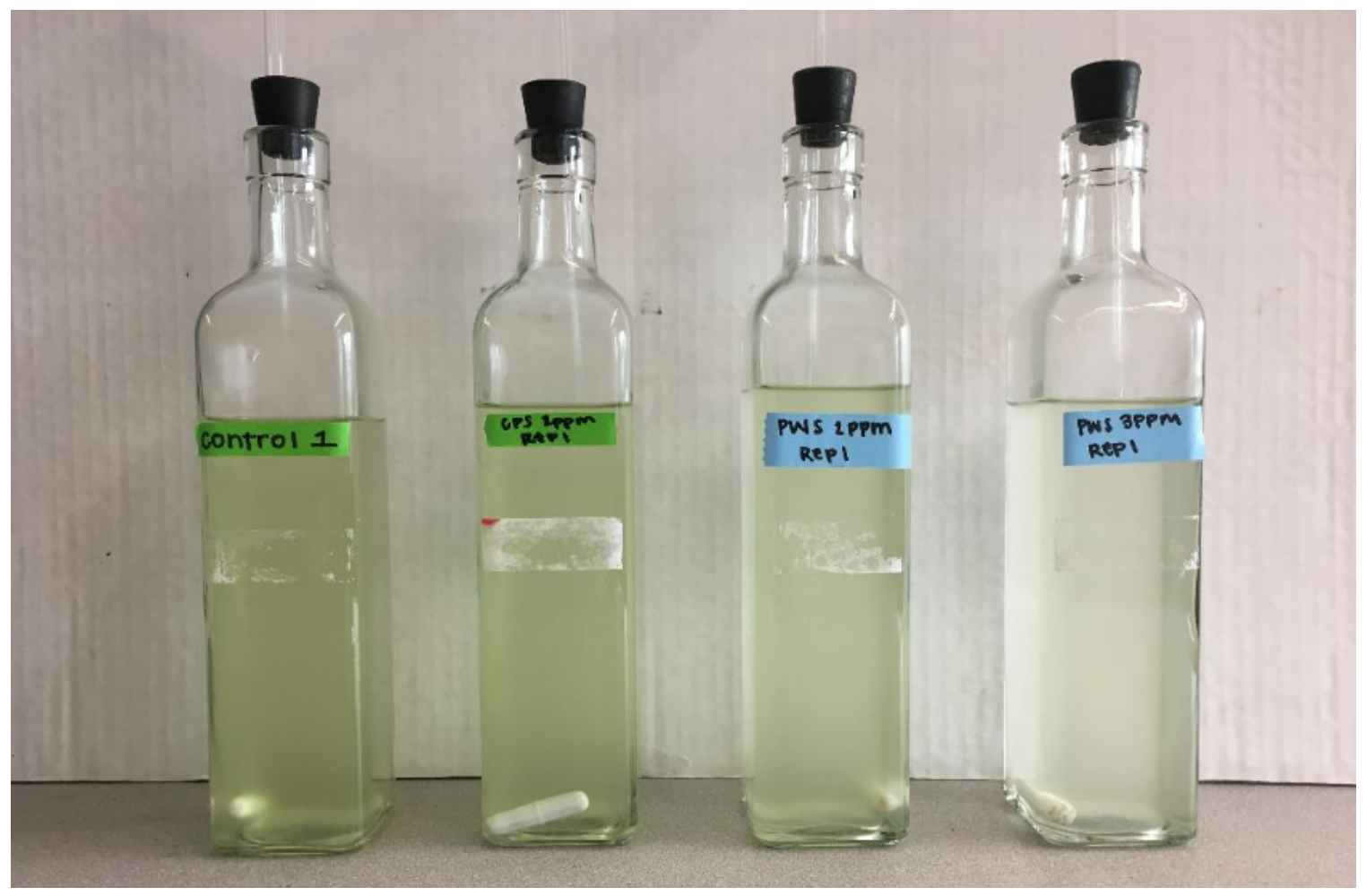

Figure 3: Visual results of ozonation of algae showing (from left to right) the control, Standard generator at $2 \mathrm{ppm}$ ozone, Ozone Plus at $2 \mathrm{ppm}$ ozone, and Ozone Plus at $3 \mathrm{ppm}$ ozone, immediately after ozone treatment.

Compared to the control, the Standard generator showed the least amount of algae killed initially, and the Ozone Plus at 3 ppm had the most algae killed initially (Figure 3 ). This result was also seen in the OD measurements that were taken initially and 24 hours after the samples were ozonated (Appendix A).

After the initial decay of the algae, the algae grew at close to normal rates due to the ideal growth conditions given in the custom light apparatus. A comparison of the 2-day and 5day optical density results of the degradation of algae experiment shows the initial decay and growth (Figure 4). 


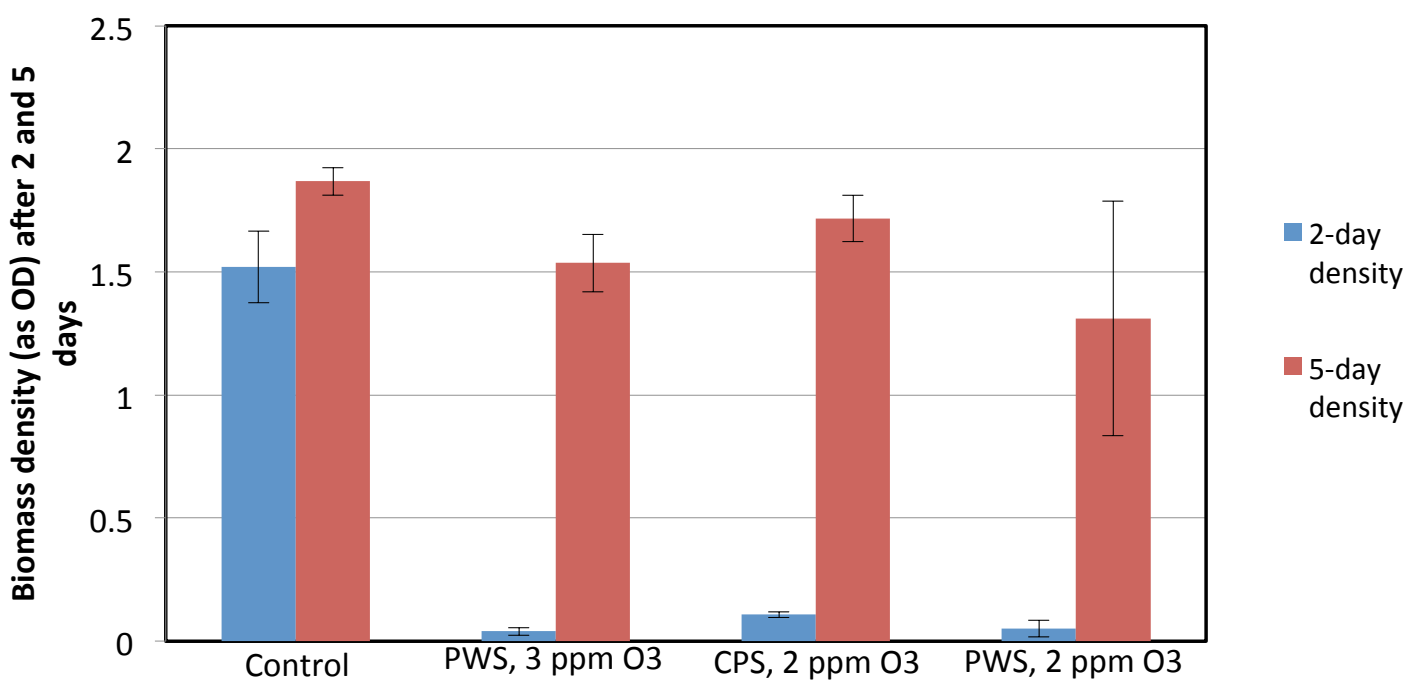

Figure 4: Optical density results of the four tests: Control, Ozone Plus at 3 ppm ozone, Standard generator at 2 ppm ozone, and Ozone Plus at 2 ppm ozone.

In the control experiment, the algae grew at a normal algal growth rate at both the 2-day and 5-day OD measurements. The Ozone Plus generator at 3 ppm concentration showed algal destruction in the 2-day density measurement. The Ozone Plus generator at $2 \mathrm{ppm}$ concentration also showed more algal destruction at the 2-day density measurement, but at a slightly lower degree than the $3 \mathrm{ppm}$. The Standard ozone generator at $2 \mathrm{ppm}$ concentration also showed more algal destruction compared to the control, at the 2-day density measurement, but at a slight lower degree than the Ozone Plus 2 ppm ozone concentration. The initial OD measurements for all the tests with added ozone did not have a significant difference.

The 5-day OD measurements were lower for all ozonated samples compared to the control, though results were much less significant than the 2-day measurements. Additionally, there was no significant difference between the three experimental systems at the 5-day growth level. 
Exposure to ozone killed most of the algae in each batch, as expected. The higher the concentration of ozone, the higher amount of algal destruction, as seen in other studies (Plummer, 1998), as indicated by comparison between the two Ozone Plus systems. This result responds to Goal 1 of this Chapter. The Ozone Plus generator had greater initial algal destruction than the Standard ozone generator, as indicated by the comparison between the results at $2 \mathrm{ppm}$ ozone concentration. This result responds to Goal 2 of this Chapter.

Regardless of initial concentration or ozone, the algae that were initially resistant to the ozone then grew at a normal rate given optimum growing conditions. This result indicated that for effective algal control, periodic ozone treatment would be needed; a single initial dose would not suffice for long-term algal removal. 


\section{Chapter 3. Ozone Effects on Organic Pharmaceuticals}

\subsection{Background}

Epilepsy affects more than 50 million people worldwide, making antiepileptic an antiseizure pharmaceuticals abundant in water (Ferreira, 2014; Kumar, 2010). Two of the most common antiepileptic drugs are phenytoin (PHT) and carbamazepine (CMZ), both of which are emerging organic contaminants (Ferreira, 2014). The molecular structures of both pharmaceuticals are shown in Figure 5.

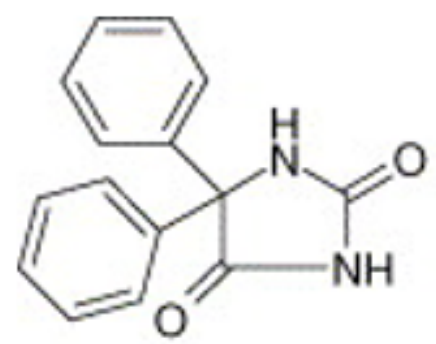

Phenytoin

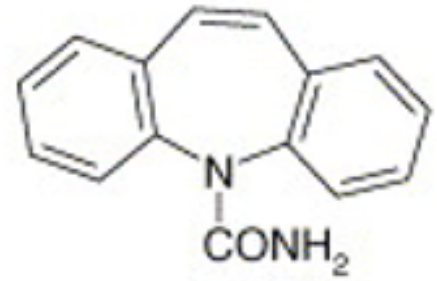

Carbamazepine

Figure 5: Molecular structure of both phenytoin and carbamazepine (Rezaei, 2004).

The median concentration in finished drinking water of PHT and CMZ is $6.2 \mathrm{ng} / \mathrm{L}$ and $2.8 \mathrm{ng} / \mathrm{L}$, respectively (Kumar, 2010). These two pharmaceuticals are especially dangerous to children and pregnant women, aquatic life, and the environment. Children and adults are exposed to both via fish consumption and accidental water consumption (Kumar, 2010). Inhalation and dermal exposure are not currently considered exposure 
methods, but could be with increasing concentrations of the pharmaceuticals in water (Kumar, 2010).

Aquatic life and the environment are exposed to these pharmaceuticals in a more direct way than humans are, thus creating more toxicity to them. The bioconcentration factor for PHT and CMZ are 3.16 L/Kg and 15.92 L/Kg, respectively (Kumar, 2010). The median concentration of PHT in stream water and fish is $5.1 \mathrm{ng} / \mathrm{L}$, while median concentration of CMZ in stream water and fish is $3.1 \mathrm{ng} / \mathrm{L}$ (Kumar, 2010).

Depending on the structure of the pharmaceutical, ozone will have different effects on pharmaceuticals in water (Von Gunten, 2003). CMZ is an ozone refractory compound, which contains multiple double bonds within its main structure, allowing it to react well with ozone (Von Gunten, 2003). PHT, on the other hand, does not have double bonds connecting major groups in its structure, only on the sides of the structure, thus the entire structure will not react well with ozone, a condition called ozone recalcitrant (Von Gunten, 2003). However, an ozone-based AOP may be effective at removing both pharmaceuticals through production of highly reactive $\cdot$ OHs (Von Gunten, 2003).

A 2014 study showed promising results for $\cdot \mathrm{OH}$ production when using ozone and surface-treated multiwalled carbon nanotubes (CNTs) (Oulton, 2014). Generally, results of this study suggest that increased concentrations of CNTs result in increased concentrations of $\cdot \mathrm{OHs}$ when those CNTs are exposed to ozone in aqueous systems. This 2014 study serves as the basis of Chapter Two and Chapter Three of this work. To 
ensure correct procedures were followed, key results of the 2014 study were duplicated successfully prior to proceeding with testing pharmaceutical degradation in this work, as seen in Appendix B (Oulton, 2014).

Two ozone generators were used to test the effects of ozone alone on anti-seizure medication: a standard ozone generator and an ozone generator thought to produce tetraoxygen as well as ozone. ClearWater Tech's CD1500P used the corona discharge method and ran on $99.9 \%$ pure oxygen from Praxair. This ozone generator produced a dissolved ozone concentration between $75-100 \mu \mathrm{M}$ after 15 minutes of ozonation. The

Ozone Plus O4 Generator used Ozone Plus Water Systems technology to produce ozone and possibly tetraozone, running on ambient air. Ozone Plus states that their technology "produces $450 \%$ longer lasting oxygen allotrope half-life than any other ozone generator in the global marketplace" (Ozone, 2016). This ozone generator produced a dissolved ozone concentration between $300-400 \mu \mathrm{M}$ after 15 minutes of ozonation. To test the effects of ozonated carbon nanotubes on anti-seizure medication, ClearWater Tech's CD1500P was used.

\subsection{Goals and Objectives}

Alternative methods to conventional water and wastewater treatment are need to treat anti-seizure medication in water, so this chapter takes a look at how efficiently ozone alone (Phase 1) and ozonated carbon nanotubes (Phase 2) break down two anti-seizure medications in water. The specific goals of this Chapter were to:

1. Determine the extent of molecular destruction in organic pharmaceuticals 
associated with varying degrees of exposure to ozone (Phase 1).

2. Compare the effects of ozone alone and ozonated carbon nanotubes degradation of ozone recalcitrant and ozone refractory anti-seizure medication (Phase 2).

\subsection{Materials and Methods}

To determine how efficiently ozone alone and ozonated carbon nanotubes treat two antiseizure medications in water, two procedures were followed. The first procedure used ozone alone to treat anti-seizure medication and was analyzed by a Total Organic Carbon analyzer. The second procedure used ozonated carbon nanotubes to treat anti-seizure medication and was analyzed by a High Performance Liquid Chromatography analyzer.

A $1 \mathrm{~g} / \mathrm{L}$ solution of surface-functionalized carbon nanotubes were sonicated for at least 30 minutes with a Branson 2800 series sonicator before use. The CNTs were initially procured from Nano Labs, Inc. and were functionalized by others (Penrose, 2017).

\subsubsection{Phase 1: Impact of Varying Degrees of Ozone on Pharmaceuticals}

To test the effects of varying degrees of ozone exposure on ozone recalcitrant and ozone refractory anti-seizure medication, the test below was performed:

Pharmaceutical solutions, at a concentration of $10.0 \mu \mathrm{M}$ for both CMZ (Fisher Scientific) and PHT (Fisher Scientific), were prepared in deionized water and filtered through a 0.45 $\mu \mathrm{m}$ filter. $21 \mathrm{~mL}$ of either the CMZ or the PHT solution was placed in 40-mL Total Organic Carbon (TOC) vials . Differing volumes of phosphate buffer (Fisher Scientific) 
and ozonated phosphate buffer (Fisher Scientific) were added to the vials as needed to achieve the desired total volume and initial ozone concentration (Table 3 and Table 4).

Ozoneated phosphate buffer was made by gas from an ozone generator bubbled into an Erlenmeyer flask holding $100 \mathrm{~mL}$ of $85 \% 5.0 \mathrm{mM}$ phosphate buffer created with potassium phosphate monobasic (Fisher Scientific) and $\mathrm{pH}$ adjusted to 7.0. This flask was placed in an ice bath to keep the temperature of the ozone solution at $4^{\circ} \mathrm{C}$. After 15 minutes of bubbling, the ozone concentrations were determined to be stable from previous tests (Appendix D). Dissolved ozone concentrations were measured using the Thermo Scientific Genesys 10S UV-Vis spectrophotometer $\left(\varepsilon_{258}=2900 \mathrm{~L} / \mathrm{mol} \mathrm{cm}\right)$ (Bader, 1981). The ozone concentrations varied between $75-400 \mu \mathrm{M}$ depending on ozone generator used.

Table 3: TOC Vial Recipe for Standard Ozone Generator

\begin{tabular}{cccc}
$\begin{array}{c}\text { No. of Vials } \\
\text { Needed }\end{array}$ & $\begin{array}{c}\text { Target Ozone } \\
\text { Concentration } \\
(\mathbf{p p m})\end{array}$ & $\begin{array}{c}\text { Ozonated } \\
\text { Phosphate Buffer } \\
(\mathbf{m L})\end{array}$ & Phosphate Buffer \\
\hline 2 & 0.220 & 21 & 0 \\
\hline 2 & 0.189 & 18 & 3 \\
\hline 2 & 0.126 & 12 & 9 \\
\hline 2 & 0.063 & 6 & 15 \\
\hline 2 & 0 & 0 & 21 \\
\hline
\end{tabular}


Table 4: TOC Vial Recipe for Ozone Plus Generator

\begin{tabular}{cccc}
$\begin{array}{c}\text { No. of Vials } \\
\text { Needed }\end{array}$ & $\begin{array}{c}\text { Target Ozone } \\
\text { Concentration } \\
(\mathbf{p p m})\end{array}$ & $\begin{array}{c}\text { Ozonated } \\
\text { Phosphate Buffer }\end{array}$ & Phosphate Buffer \\
\hline 2 & 0.220 & 21 & $\mathbf{( m L )}$ \\
\hline 2 & 0.189 & 18 & 0 \\
\hline 2 & 0.126 & 12 & 3 \\
\hline 2 & 0.063 & 6 & 15 \\
\hline 2 & 0 & 0 & 21 \\
\hline
\end{tabular}

Immediately following the addition of ozonated phosphate buffer, $20 \mu \mathrm{M}$ sodium sulfite (Fisher Scientific) was added to quench any reaction with ozone. Samples were acidified with a concentrated $25 \%$ phosphoric acid, capped, and inverted three times. The samples were then analyzed using a TOC-V CPH/CPN Total Organic Analyzer. Both total carbon present and inorganic carbon were measured and the non-purgeable organic carbon (NPOC) measurements were taken.

\subsubsection{Phase 2: Ozonated CNT Exposure on Pharmaceuticals in Simple Model Water} Systems

To test the effects of ozone and multiwalled carbon nanotube exposure on ozone recalcitrant and ozone refractory anti-seizure medication, the test below was performed:

A sample of $100 \mathrm{~mL}$ of $85 \% 5 \mathrm{mM}$ phosphate buffer (pH 7) was ozonated. After 15 minutes of ozonation, $15 \mathrm{~mL}$ of the solution was added to a beaker already mixing on a 
stir plate with $1 \mathrm{~mL} 0.02 \mathrm{mM}$ PHT or $1 \mathrm{~mL} 0.02 \mathrm{mM} \mathrm{CMZ}$, and $1.28 \mathrm{~mL}$ of $5 \mathrm{mM}$ tertButyl alcohol. At the same time, sonicated mulitwalled carbon nanotubes were added to achieve a solid loading of either $10 \mathrm{ppm}$ or $20 \mathrm{ppm}$. Each experiment was performed in triplicate, and ozone-free, CNT-free, and ozone-and-CNT-free controls were tested as well.

At times $5,15,30,60,90$, and 120 seconds, $500 \mu \mathrm{L}$ of solution in the beaker was added to the Indigo Blue microcentrifuge tubes (discussed below) and $1000 \mu \mathrm{L}$ of solution was added to separate microcentrifuge tubes which contained $25 \mu \mathrm{L}$ of $0.2 \mathrm{mM}$ of sodium sulfite $(160 \mu \mathrm{M})$ to quench the ozone reaction at the time of sampling. These samples were filtered through $0.2 \mu \mathrm{m}$ filters and transferred to HPLC vials for subsequent analysis.

The Indigo Blue (IB) test was performed to understand how the ozone degraded as the reaction proceeded. Ozone breaks the double bonds on the indigle trisulfonate molecule, which means when the ozone solution is mixed with the IB solution, the IB solution color will reduce. This reaction usually happens instantaneously. Each IB cuvette contained a solution of $100 \mu \mathrm{L}$ of $0.5 \mathrm{M}$ phosphoric acid, $500 \mu \mathrm{L}$ deionized water, and $50 \mu \mathrm{L}$ of IB reagent prepared according to standard methods (Bader, 1981). These IB samples were transferred to plastic cuvettes and read at $600 \mathrm{~nm}$ on the UV-Vis Spectrophotometer to determine ozone concentration.

Samples were analyzed with the HPLC for determination of CMZ and PHT 
concentrations. The eluent for this process consisted of $72 \%$ deionized water, $23 \%$ acetonitrile, and $5 \%$ methanol, $\mathrm{pH}$ adjusted to 7.0 . The HPLC ran at $0.430 \mathrm{~mL} /$ minute for 60 minutes per vial, and results were measured at a $220 \mathrm{~nm}$ wavelength.

\subsection{Results and Discussion}

In Phase 1, the TOC test results were compared for both the CMZ and PHT with both ozone generators (Figure 6).

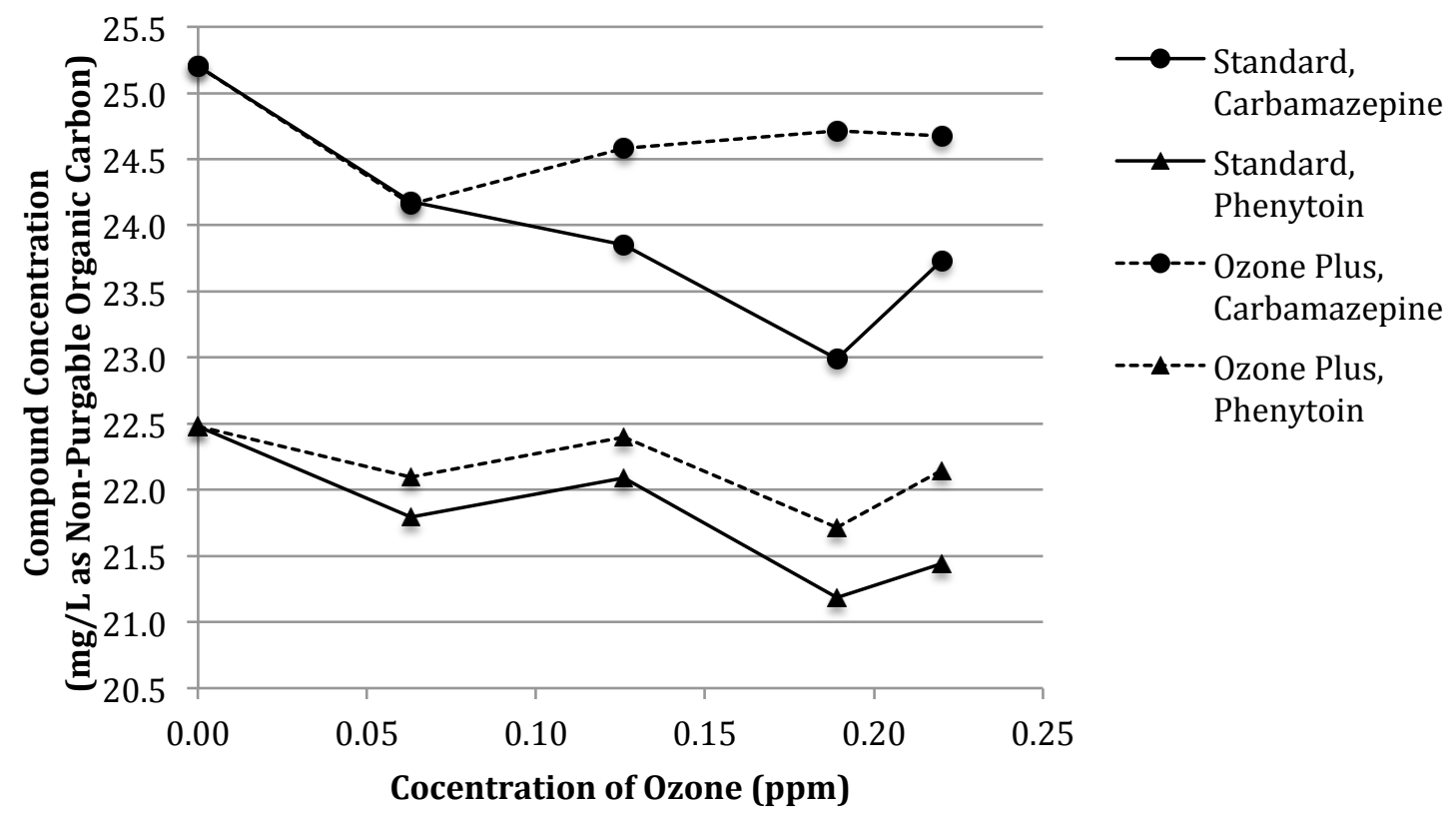

Figure 6: Comparison of concentration of ozone verses concentration of non-purgable organic carbon (Phase 1) with three trials each.

These results show that the presence of ozone did have some level of destruction on both CMZ and PHT. The standard ozone generator degraded CMZ and PHT more effectively than the Ozone Plus generator, unlike the algae results in Chapter Two.

The pharmaceutical destruction to ozone dose relationship was expected to be linear. While there is a general trend indicating greater destruction with greater concentration, 
this result is not definitive, as indicated by the increased concentration seen for all experiments at $3.5 \mathrm{ppm}$ compared to $2.75 \mathrm{ppm}$. Additionally, the CMZ concentration shows a generally level trend after exposure to Ozone Plus, indicating destruction is independent of ozone concentration. Note also that concentrations go from approximately $25 \mathrm{ppm}(\mathrm{CMZ})$ or $22.5 \mathrm{ppm}$ (PHT) and shows a maximum reduction of less than $10 \%$ for any level of ozone. Again, this degradation may be within the instrument error level, so these results cannot be considered definitive.

It should also be noted that Phase 1 measured TOC reduction, not degradation of the specific pharmaceutical itself. The TOC level may include non-purgeable pharmaceutical breakdown products, so these values are not strictly indicative of breakdown of the pharmaceuticals tested.

The TOC test to determine the extent of molecular destruction in CMZ and PHT associated with varying degrees of exposure to ozone results were inconclusive due to the maximum reduction of less than $10 \%$ for any level of ozone.

In Phase 2, pharmaceutical concentrations were measured using the HPLC. Results discussed below do not reflect presence of remaining breakdown products in solution. The normalized HPLC data for the CMZ simple model tests was compared against the ozone-free controls (Figure 7). 


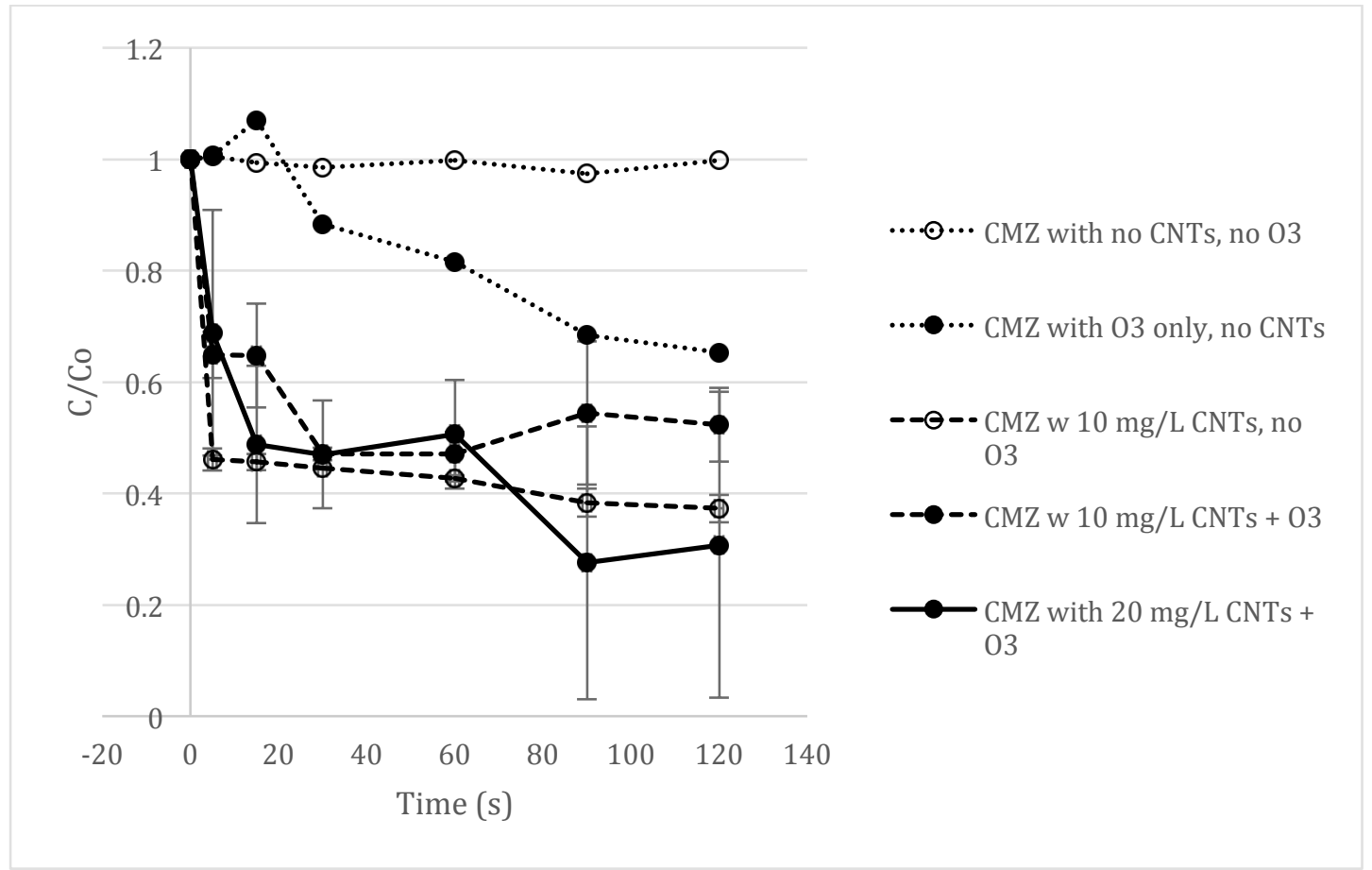

Figure 7: Degradation of CMZ in simple model water systems all trials with an initial ozone concentration of approximately $65 \mu \mathrm{M}$.

As seen above with the unfilled circles and the dotted line, CMZ with no CNTs and no ozone did not degrade. It has a mean of 1.0 and a standard deviation of 0.02 .

The degradation of CMZ with ozone and no CNT loading was approximately $35 \%$ and it had a mean of 0.65 . CMZ with a CNT loading of $10 \mathrm{ppm}$ and no ozone had a degradation of approximately $63 \%$, which suggests sorption of CMZ onto the CNTs. This can be seen above with the unfilled circle and the dashed line. It had a mean of 0.37 and a standard deviation of 0.25 . CMZ with a CNT loading of $10 \mathrm{ppm}$ and ozone had a degradation of approximately $48 \%$ and a mean of 0.53 . This can be seen above with the filled circle and the dashed line. It was expected that the CMZ with a 10 ppm CNT loading with ozone would have a greater degradation than CMZ with a $10 \mathrm{ppm}$ CNT loading without ozone due to the anticipated $\cdot \mathrm{OH}$ formation; however, this result likely 
indicates that most of the CMZ removal can be attributed to CNT sorption, rather than oxidative degradation, or that $\cdot \mathrm{OH}$ formation was not significant. Seen above with the filled circle and solid line, CMZ with a CNT loading of $20 \mathrm{ppm}$ and ozone had a degradation of approximately $70 \%$ and mean of 0.3 . This result had approximately $20 \%$ increased degradation with the increased CNT loading. This suggests $\cdot \mathrm{OH}$ were produced and had an effect on the degradation of CMZ, but it is not definitive.

The normalized HPLC data for the PHT controlled tests was compared against the PHT controls (Figure 8).

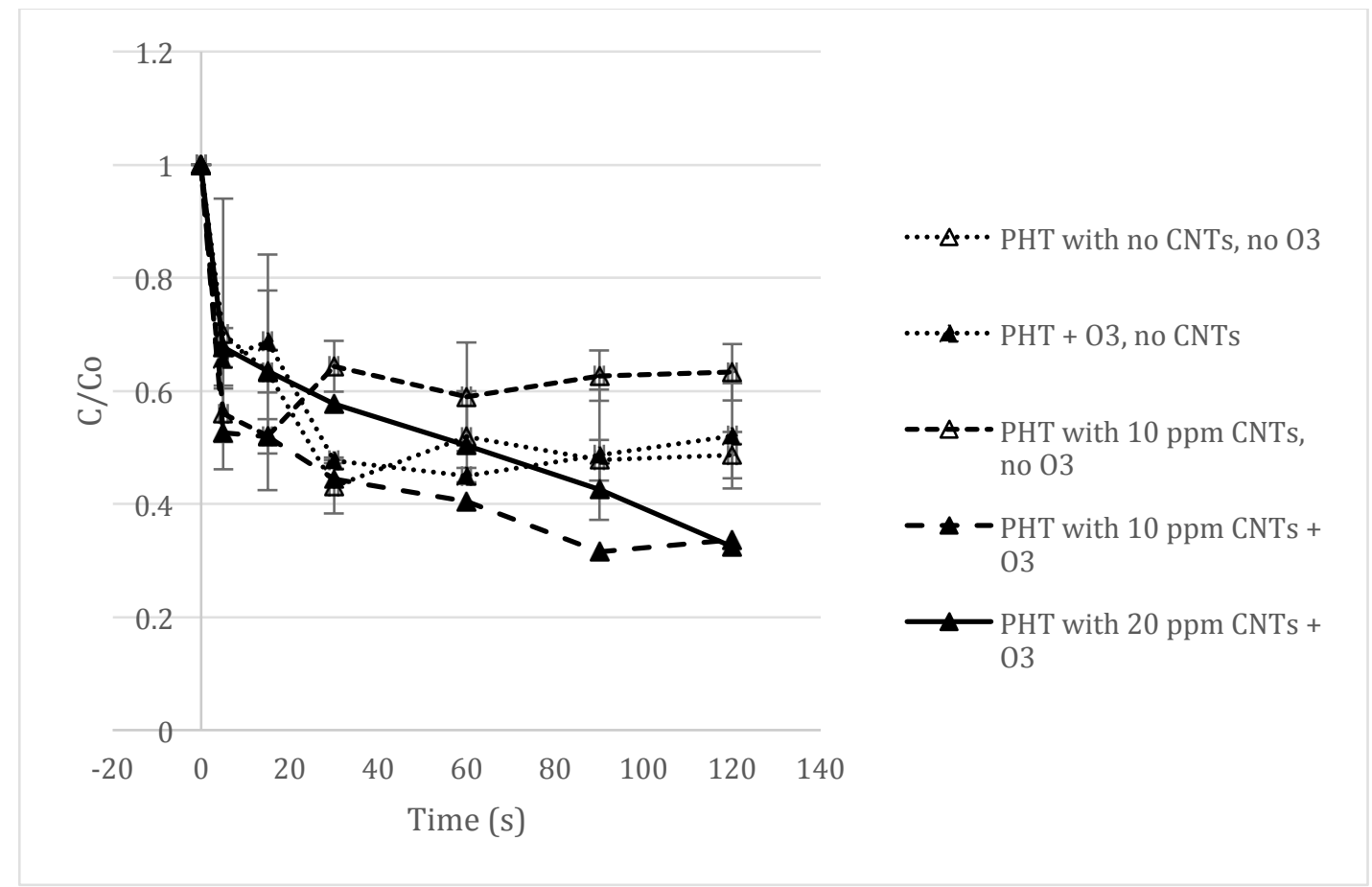

Figure 8: Degradation of PHT in the controlled media tests with all trials with an initial ozone concentration of approximately $65 \mu \mathrm{M}$.

PHT did degrade approximately $16 \%$ in an aqueous solution in the control solution with no ozone and no CNT loading over the two minute test, and it had a mean of 0.84 . This 
is seen above with the unfilled triangle and dotted line. As no degradation was anticipated for the control, this concentration decrease represents a possible source of error in the results. The degradation of PHT with ozone and no CNT loading was approximately $48 \%$, with the majority of the degradation happening within the first 30 seconds. This is seen above with the filled triangle and the dotted line. It had a mean of 0.52. PHT with a CNT loading of $10 \mathrm{ppm}$ and no ozone had a degradation of approximately $62 \%$, which suggests sorption happened during this test. This can be seen above in the unfilled triangle and dashed line. It had a mean of 0.38. PHT with a CNT loading of $10 \mathrm{ppm}$ and ozone had a degradation of approximately $67 \%$, this can be seen above with the filled triangle and dashed line. It had a mean of 0.33 and a standard deviation of 0.11 . This result likely indicates that most of the PHT removal can be attributed to CNT sorption, rather than oxidative degradation. PHT with a CNT loading of $20 \mathrm{ppm}$ and ozone had a degradation of approximately $68 \%$. This can be seen above with the filled triangle and solid line. It had a mean of 0.32 and a standard deviation of 0.11. This result likely indicates that most of the PHT removal can be attributed to CNT sorption, rather than oxidative degradation.

Phase 2 showed that CMZ had the most degradation with a CNT loading of $20 \mathrm{ppm}$ and ozone over two minutes. This suggests $\cdot \mathrm{OH}$ were produced and had an effect on the degradation of CMZ. PHT had the most degradation (68\%) with a CNT loading of 20 ppm and ozone.

In Phase 1, TOC tests were used determine the extent of molecular destruction in CMZ 
and PHT associated with varying degrees of exposure to ozone. These results were inconclusive due to the maximum reduction of less than $10 \%$ for any level of ozone. In Phase 2, the HPLC analyzed the percent degradation of pharmaceuticals in various aqueous solutions. Both CMZ and PHT had degradation percentages similar for the ozone-free controls. 


\section{Chapter 4. Ozone and AOP Effects on Complex Water Systems}

\subsection{Background}

While Chapter Three of this research focused on using simplified water systems for control purposes, complex water is a more representative system for real life application. This chapter focuses on degradation of the ozone refractory compound, PHT; CMZ was included in these studies as a competitive contaminant. For Phase 1 of this study, the simple model water system from Chapter Three was replicated, with a mixture of the two pharmaceuticals rather than a single pharmaceutical at a time. For Phase 2, treated effluent wastewater was used with the pharmaceutical mixture, to better understand the outcomes since this treatment would ideally come after the final standard treatment at a wastewater treatment plant.

\subsection{Goals and Objectives}

The research objective of Chapter Four was to determine how efficiently ozone and carbon nanotubes break down anti-seizure medication in complex water systems, to better understand implications for eventual real life application. The specific goals of this chapter were to:

1. Replicate previous studies from Chapter Three with a more complex media (Phase 1).

2. Replicate Phase 1 tests with a treated effluent wastewater (Phase 2). 


\subsection{Materials and Methods}

Most of the materials, procedures, and analytical methods in Chapter Four are identical to those discussed in Chapter Three, Phase 2. Additions and deviations for this Chapter are discussed below.

Pharmaceuticals and model water system components from Chapter Three were replicated for this Chapter. The wastewater used in Chapter Four Phase 2 came from the effluent spout of the San Luis Obispo Wastewater Treatment Plant in San Luis Obispo, California obtained on 5-23-17. The typical $\mathrm{pH}$ value of this water is 7.0 and the TSS is typically less than $12 \mathrm{mg} / \mathrm{L}$ (Ouellette, 2017).

\subsubsection{Simple Model System with Pharmaceutical Mixture Procedure}

A mixture of pharmaceuticals was used as an intermittent step between the simple model water system from Chapter Three, Phase 2 and the wastewater system discussed below. In this case, instead of using just one of the pharmaceuticals, the beaker on the stir plate initially had $1 \mathrm{~mL}$ of $0.02 \mathrm{mM} \mathrm{PHT,} 1 \mathrm{~mL}$ of $0.02 \mathrm{mM} \mathrm{CMZ}$, and $1.28 \mathrm{~mL}$ of $5 \mathrm{mM} \mathrm{t}-$ BTA combined in it, prior to addition of the ozonated phosphate buffer. The rest of the procedure can be found in Chapter Three.

\subsubsection{Wastewater Media Procedure}

A sample of $100 \mathrm{~mL}$ of effluent water from the San Luis Obispo Wastewater Treatment Plant was ozonated. After 10 minutes of ozonation, $15 \mathrm{~mL}$ of the sample was added to a beaker already mixing on a stir plate with $1 \mathrm{~mL}$ of $0.02 \mathrm{mM} \mathrm{PHT,} 1 \mathrm{~mL}$ of $0.02 \mathrm{mM}$ 
$\mathrm{CMZ}$, and $1.28 \mathrm{~mL}$ of t-BTA. At the same time, sonicated multiwalled carbon nanotubes were added to create either $10 \mathrm{ppm}$ or $20 \mathrm{ppm}$ CNT solid loading in the reactor. As in Chapter 2, triplicate experiments were performed, and ozone-free, CNT-free, and ozoneand-CNT-free control experiments were conducted.

Sampling and analysis procedures were conducted as described in Chapter Three.

\subsection{Results and Discussion}

Listed below are the results for both the simple model water system with pharmaceutical mixture (MIX) (Phase 1) and the wastewater media experiments (Phase 2). As discussed in Chapter Three, CMZ reacted promptly with ozone, producing an unknown breakdown product. Therefore, these results are for PHT only. The CMZ results can be found in Appendix C.

\subsubsection{Phase 1: Simple Model Water System with MIX}

The results of PHT in the controlled complex media tests were compared to the results of the PHT controlled tests from Chapter Three and PHT controls (Figure 9). 


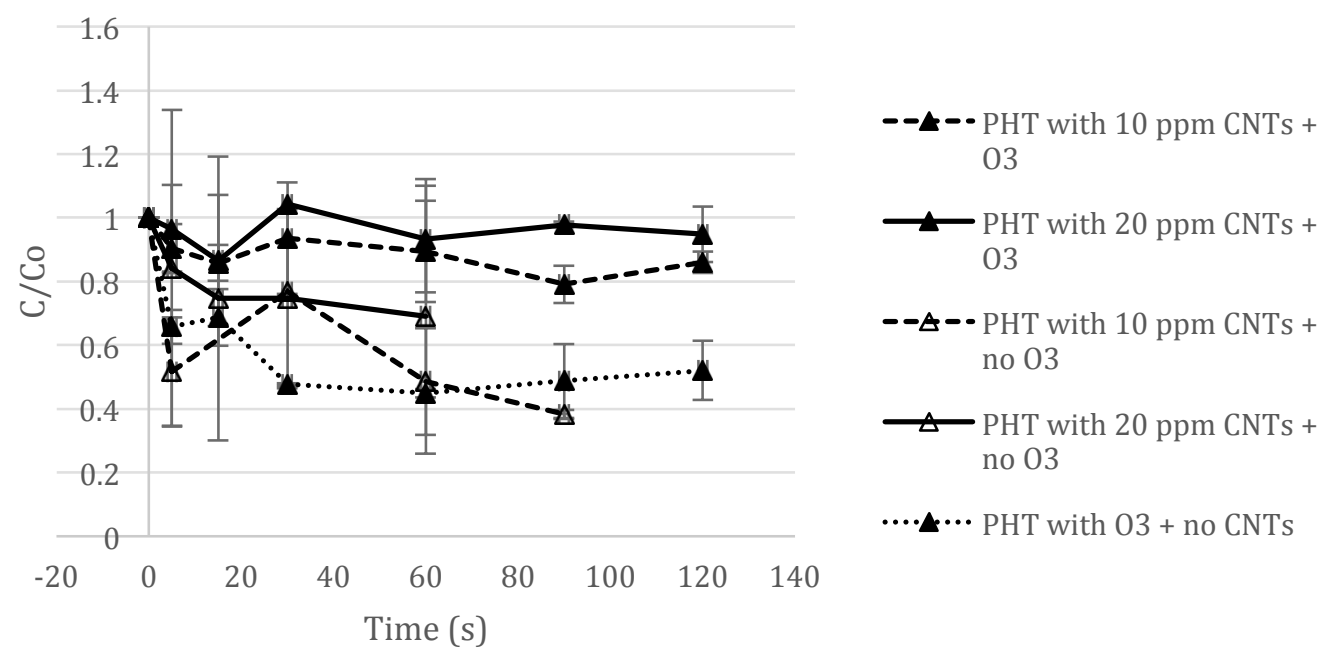

Figure 9: Degradation of PHT in the MIX tests with comparison to controls.

PHT with ozone only had a degradation of $48 \%$, as seen above in the filled triangle and dotted line. It had a mean of 0.52 and a standard deviation of 0.09 after two minutes. PHT with a solid loading of $10 \mathrm{ppm}$ of CNTs, as seen above in the unfilled triangle and dashed line, had a degradation of $62 \%$, a mean of 0.49 , and a standard deviation of 0.17 . PHT with no ozone and 20 ppm of CNTs, seen above with an unfilled triangle and a solid line, had degradations of $31 \%$, a mean of 0.69 , and a standard deviation of 0.43 . PHT with 10 ppm CNTs and ozone had a degradation of approximately $14 \%$. This can be seen above with the filled triangle and dashed line. It had a mean of 0.86 and a standard deviation of 0.03 . PHT with 20 ppm CNTs and ozone had a degradation of approximately 5\%. This can been seen above with the filled triangle and the solid line. It had a mean of 0.95 and a standard deviation of 0.09 . These results with ozone are lower than those without ozone, showing the opposite of what was expected, most likely due to the addition of organics with the $\mathrm{CMZ}$. It is easier for the ozone and $\cdot \mathrm{OH}$ react with the 
$\mathrm{CMZ}$ than the PHT, and the degradation of the CMZ is most likely using up the ozone and $\cdot \mathrm{OH}$ before it degrades the PHT.

\subsubsection{Phase 2: Wastewater Media}

The results of PHT in the wastewater media (WW) tests were compared to the results of the PHT controlled tests from Chapter Three and PHT controls (Figure 10).

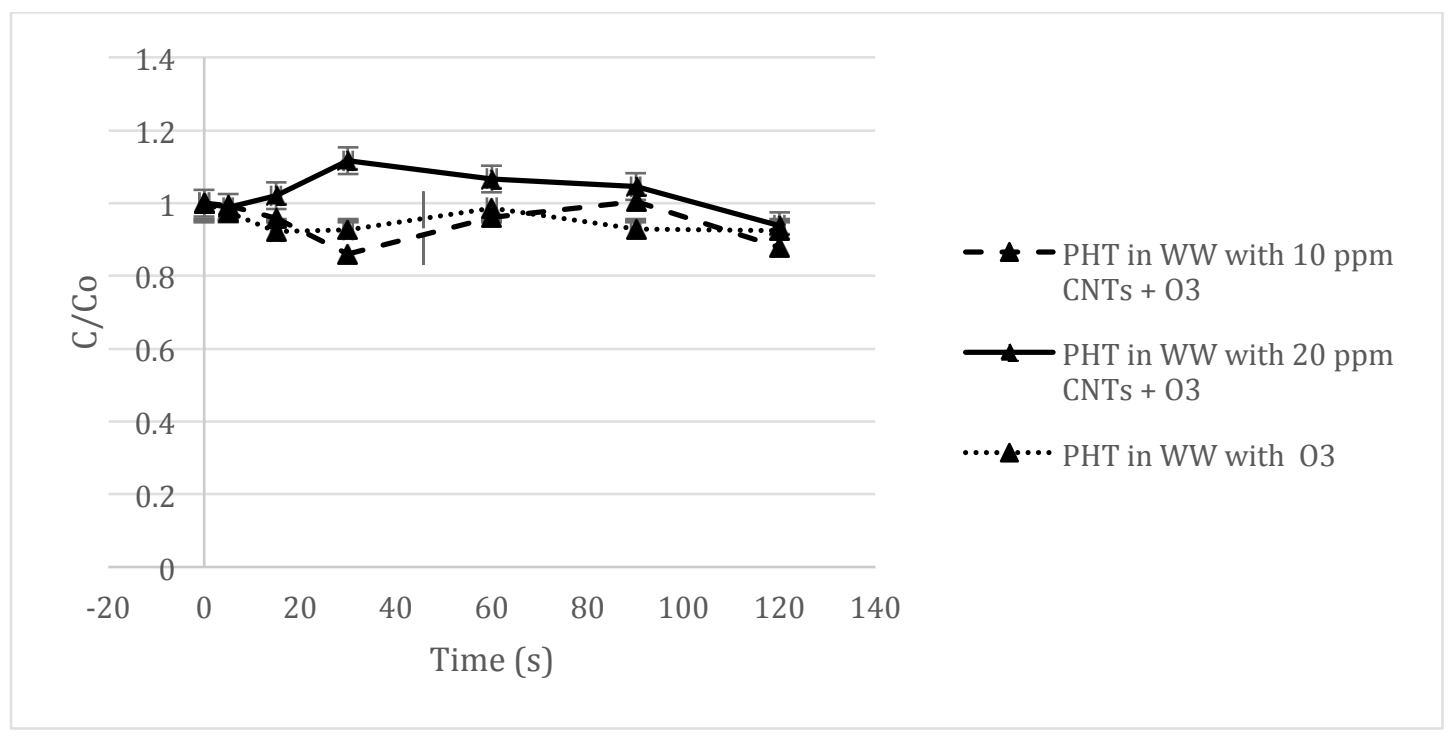

Figure 10: Degradation of PHT in the WW tests with comparison to control.

PHT in ozonated wastewater with no CNTs degraded approximately $8 \%$ in two minutes, as seen with the dotted line in Figure 10. It had a mean of 0.92 and a standard deviation of 0.11 . PHT in ozonated wastewater with a solid loading of $10 \mathrm{ppm}$ CNTs had a degradation of $12 \%$, as seen above in the dashed line. After two minutes, it had a mean of 0.88 and a standard deviation of 0.05 . In the solid line, PHT in ozonated wastewater with a solid loading of $20 \mathrm{ppm}$ CNTs had a degradation of $6 \%$. It had a mean of 0.94 and 
a standard deviation of 0.04 after two minutes. In this case, all of the percentages were within $10 \%$ of each other, indicating no evidence of actual degradation.

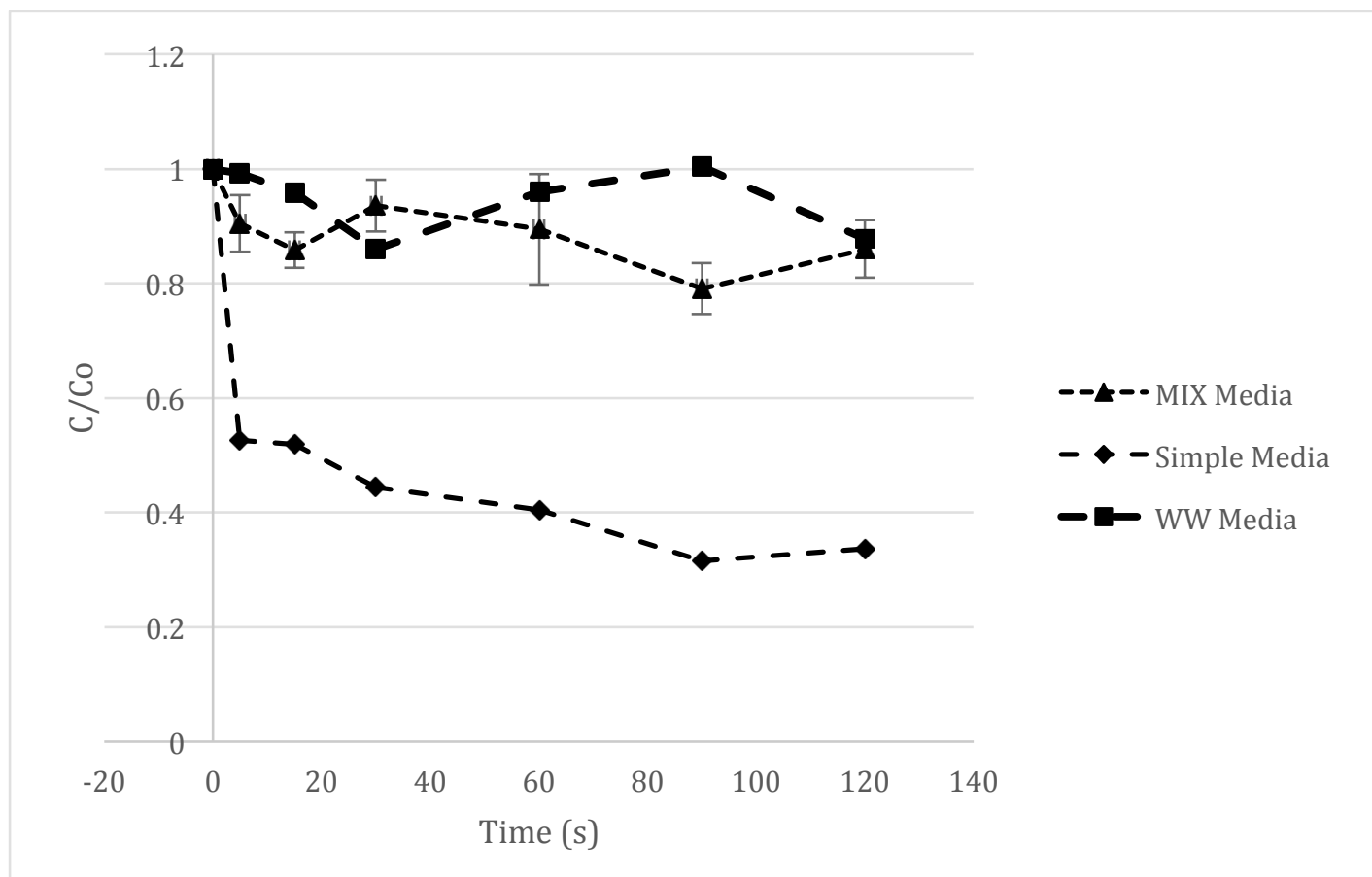

Figure 11: Comparison of degradation of PHT with ozone and $10 \mathrm{mg} / \mathrm{L} \mathrm{CNT}$ solid loading in simple media, MIX media, and WW media.

The overall comparison of the degradation of PHT in different medias shows the more complex the media is, the less PHT will degrade. The increase of organics in the more complex medias are likely reacting with the ozone and $\cdot \mathrm{OH}$, using up all the ozone, and leaving PHT in the media. 


\section{Chapter 5. Conclusions and Future Work}

In Chapter Two, Anabaena algal cultures were destroyed by all three ozone concentrations used in Chapter Two. Ozone Plus's 3 ppm ozone concentration was the most optimal as it had the lowest average OD measurements initially and after 2-days. The study shows that treated or surviving algae will grow back to its growth maximum after approximately 5 -days.

In Chapter Three, a TOC test was used to determine the extent of molecular destruction in $\mathrm{CMZ}$ and PHT associated with varying degrees of exposure to ozone. The pharmaceutical destruction to ozone dose relationship was expected to be linear, but these results were inconclusive due to the maximum reduction of less than $10 \%$ for any level of ozone.

In Chapter Four, the simple media tests, CMZ had a degradation of $63 \%$ and $70 \%$ with ozone and a CNT loading of $10 \mathrm{ppm}$ and $20 \mathrm{ppm}$, respectively. This suggests $\cdot \mathrm{OH}$ were produced and had an effect on the degradation of CMZ. PHT had the most degradation with a CNT loading of $10 \mathrm{ppm}$ and no ozone. This test suggests sorption had a greater effect on the pharmaceuticals than ozone or $\cdot \mathrm{OH}$ did.

In the simple water system MIX tests, the results were not as expected. PHT with $10 \mathrm{ppm}$ CNTs and ozone had a degradation of approximately 14\%. PHT with 20 ppm CNTs and ozone had a degradation of approximately 5\%, while the controls had much larger degradation percentages. This was most likely due to the increased organics in the MIX 
test. The ozone and $\cdot \mathrm{OH}$ reacted with the added organics instead of the PHT.

In the WW tests, PHT with a CNT loading of $10 \mathrm{ppm}$ had a degradation of $12 \%$ and $6 \%$ for a CNT loading of $20 \mathrm{ppm}$. The low degradation rate is most likely due to ozone and CNT reacting with other organic matter in the reactor and not the PHT.

The comparison of the degradation of PHT with ozone and a CNT solid loading of 10 ppm in the three different medias shows the more complex the media is, the less PHT will degrade. Again, the increase of organics in the more complex medias are likely reacting with the ozone and $\cdot \mathrm{OH}$ and using up the ozone.

Ozone was successfully used to reduce emerging organic contaminants. Ozone and $\cdot \mathrm{OH}$ were successfully used to treat PHT and CMZ in simple water systems and less successfully in more complicated water systems. These results suggest that ozone and hydroxyl radicals generated from ozonated CNTs have potential to be an effective alternative to current AOPs.

Based on the results of this research, further studies are needed to have a more conclusive understanding on how to most effectively degrade pharmaceuticals during water or wastewater treatment. The biggest challenge with this research was the standard ozone generator used could not produce high levels of dissolved ozone concentration. Research with higher concentrations of ozone would allow analysis to further understand how these pharmaceuticals degrade. Further research also includes the same procedure as the controlled tests with the pharmaceuticals, no ozone, and no CNTs to see if there is any 
degradation happening in an aqueous system. Further research should also include continuous treatment, instead of batch treatments, to have a more real-life application.

Before a real-life application, further research on ozonation by-products needs to be done. The by-products of this application, including the breakdown products of the pharmaceuticals and disinfection by-products (DBPs), could have a more harmful effect than the contaminated water. The breakdown products could still be pharmaceutically active, needing more treatment. Some DBPs are known carcinogens, making these byproducts extremely harmful.

The research should be expanded to understand the effects of ozone on other emerging organic compounds. The pharmaceutical research should also be expanded to see if the same processes could treat other ozone refractory pharmaceuticals. 


\section{REFERENCES}

Abdelmelek, S. B., Greaves, J., Ishida, K. P., Cooper, W. J., \& Song, W. (2011). Removal of Pharmaceutical and Personal Care Products from Reverse Osmosis Retentate Using Advanced Oxidation Processes. Environmental Science \& Technology, 45(8), 3665-3671.

Bader, H. and J. Hoigne, Determination of ozone in water by the indigo method. Water Research, 1981. 15(4): p. 449-456.

Fawell, J., \& Nieuwenhuijsen, M. J. (2003, December 01). Contaminants in drinking water Environmental pollution and health. Retrieved May 18, 2017.

Ferreira, A., Rodrigues, M., Oliveira, P., Francisco, J., Fortuna, A., Rosado, L., . . Alves, G. (2014). Liquid chromatographic assay based on microextraction by packed sorbent for therapeutic drug monitoring of carbamazepine, lamotrigine, oxcarbazepine, phenobarbital, phenytoin and the active metabolites carbamazepine-10,11-epoxide and licarbazepine. Journal of Chromatography $B, 971,20-29$.

Ikehata, K., Naghashkar, N. J., \& El-Din, M. G. (2006). Degradation of Aqueous Pharmaceuticals by Ozonation and Advanced Oxidation Processes: A Review. Ozone: Science \& Engineering, 28(6), 353-414.

Kumar, A., \& Xagoraraki, I. (2010). Human health risk assessment of pharmaceuticals in water: An uncertainty analysis for meprobamate, carbamazepine, and phenytoin. Regulatory Toxicology and Pharmacology, 57(2-3), 146-156.

Lippelt, Jana. DICE Report; Munich 13.4 (Winter 2015): 65-67.

Loeb, B. L., Thompson, C. M., Drago, J., Takahara, H., \& Baig, S. (2012). Worldwide Ozone Capacity for Treatment of Drinking Water and Wastewater: A Review. Ozone: Science \& Engineering, 34(1), 64-77.

Miao, H., \& Tao, W. (2009). The mechanisms of ozonation on cyanobacteria and its toxins removal. Separation and Purification Technology, 66(1), 187-193.

Ouellette, Pam. “SLO WWTP Effluent Wastewater Qualities.” 28 Aug. 2017.

Oulton, R. L., Kohn, T., \& Cwiertny, D. M. (2010). Pharmaceuticals and personal care products in effluent matrices: A survey of transformation and removal during wastewater treatment and implications for wastewater management. Journal of Environmental Monitoring, 12(11), 1956.

Oulton, R. L. (2014). "Development of Nanomaterial-Enabled Advanced Oxidation Techniques for Treatment of Organic Micropollutants." 
Ozone Plus - Water Treatment Systems. (2017). Retrieved June 11, 2017, from http://ozoneplus.com/.

Pal, A., He, Y., Jekel, M., Reinhard, M., \& Gin, K. Y. (2014). Emerging contaminants of public health significance as water quality indicator compounds in the urban water cycle. Environment International, 71, 46-62.

Plummer, J., \& Edzwald, J. (1998). Effect of ozone on disinfection by-product formation of algae. Water Science and Technology, 37(2), 49-55.

Rezaei, Z. (2004). Simultaneous spectrophotometric determination of carbamazepine and phenytoin in serum by PLS regression and comparison with HPLC. Talanta.

Spence, W. H. (2016). Regrowth Of Chlorella Sorokiniana On Recycled Media With Replenished Nutrients.

Von Gunten, U. (2003). Ozonation of drinking water: Part I. Oxidation kinetics and product formation. Water Research, 37(7), 1443-1467. 


\section{APPENDICES}

\section{Appendix A: Optical Density Measurements for Algal Destruction}

Table A: The Five-Day Optical Density Measurements for the Control, Ozone Plus 3 ppm, Standard 2 ppm, and Ozone Plus 2 ppm

\begin{tabular}{ccccccc}
\hline Identifier & $\begin{array}{c}\text { OD, } \\
\text { Initial }\end{array}$ & $\begin{array}{c}\text { OD, } \\
\mathbf{2 4 - h r}\end{array}$ & $\begin{array}{c}\text { OD, } \\
\mathbf{4 8 - h r}\end{array}$ & $\begin{array}{c}\text { OD, } \\
\mathbf{7 2 - h r}\end{array}$ & $\begin{array}{c}\text { OD, } \\
\text { 96-hr }\end{array}$ & $\begin{array}{c}\text { OD, } \\
\mathbf{1 2 0}-\mathbf{h r}\end{array}$ \\
\hline Control 1 & & 0.284 & 1.404 & 1.8 & 1.86 & 1.932 \\
Control 2 & 0.110 & 0.284 & 1.474 & 1.956 & 1.924 & 1.844 \\
Control 3 & & 0.279 & 1.684 & 1.904 & 1.97 & 1.828 \\
\hline Ozone Plus, 3ppm 1 & & 0.046 & 0.046 & 0.1 & 0.96 & 1.404 \\
Ozone Plus, 3ppm 2 & 0.115 & 0.052 & 0.052 & 0.108 & 0.942 & 1.626 \\
Ozone Plus, 3ppm 3 & & 0.006 & 0.022 & 0.257 & 0.55 & 0.789 \\
\hline Standard, 2ppm 1 & & 0.046 & 0.101 & 0.922 & 1.5 & 1.784 \\
Standard, 2ppm 2 & \multirow{2}{*}{0.113} & 0.046 & 0.102 & 0.967 & 1.56 & 1.61 \\
Standard, 2ppm 3 & & 0.048 & 0.122 & 0.931 & 1.68 & 1.756 \\
\hline Ozone Plus, 2ppm 1 & & 0.032 & 0.02 & 0.06 & 0.727 & 0.778 \\
Ozone Plus, 2ppm 2 & \multirow{2}{*}{0.098} & 0.051 & 0.086 & 0.116 & 0.677 & 1.462 \\
Ozone Plus, 2ppm 3 & & 0.043 & 0.045 & 0.113 & 1.1 & 1.696 \\
\hline
\end{tabular}


Appendix B: Replication of p-CBA Tests From Previous Studies (Oulton, 2014)

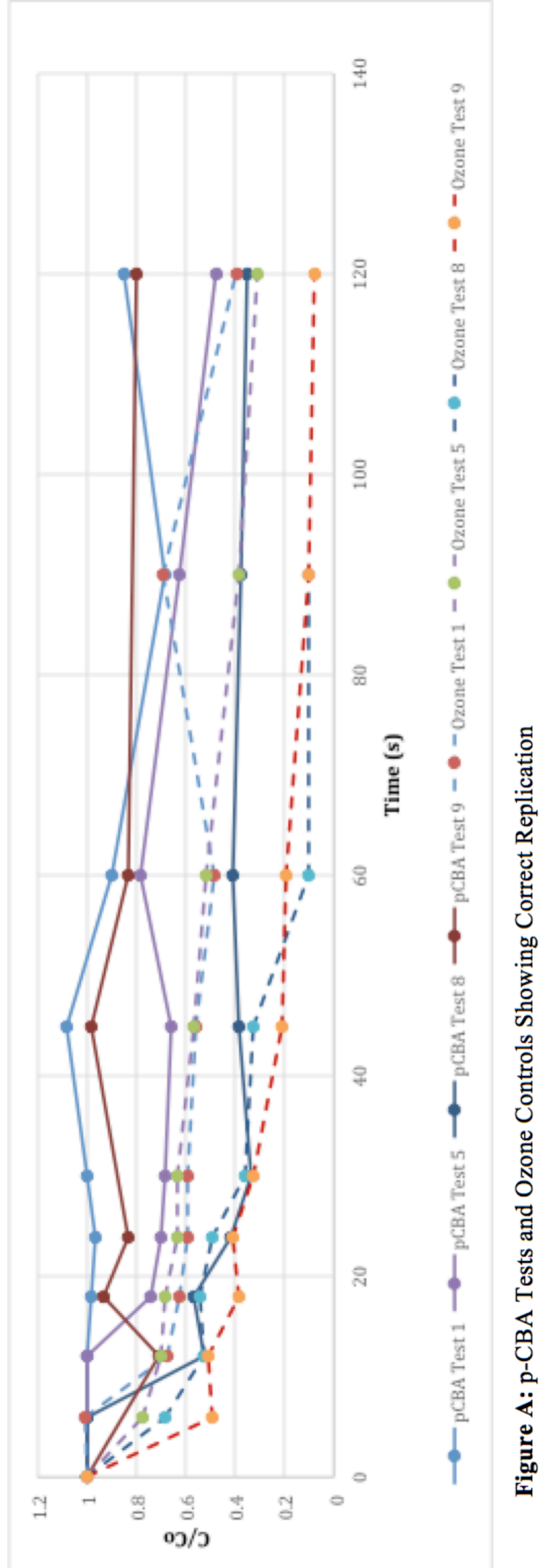




\section{Appendix C: The results of CMZ in the MIX tests and wastewater tests}

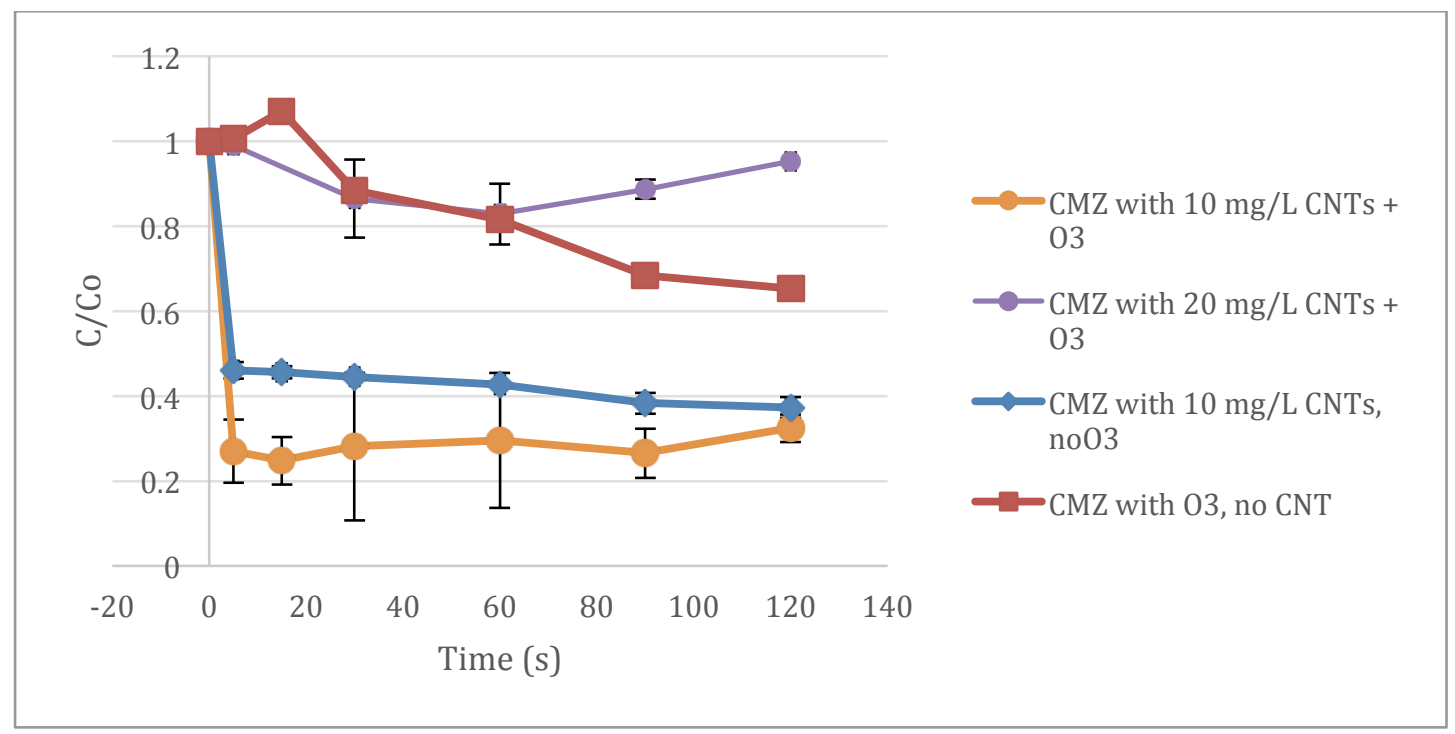

Figure B: Degradation of CMZ in the mixed media tests with comparison to controls.

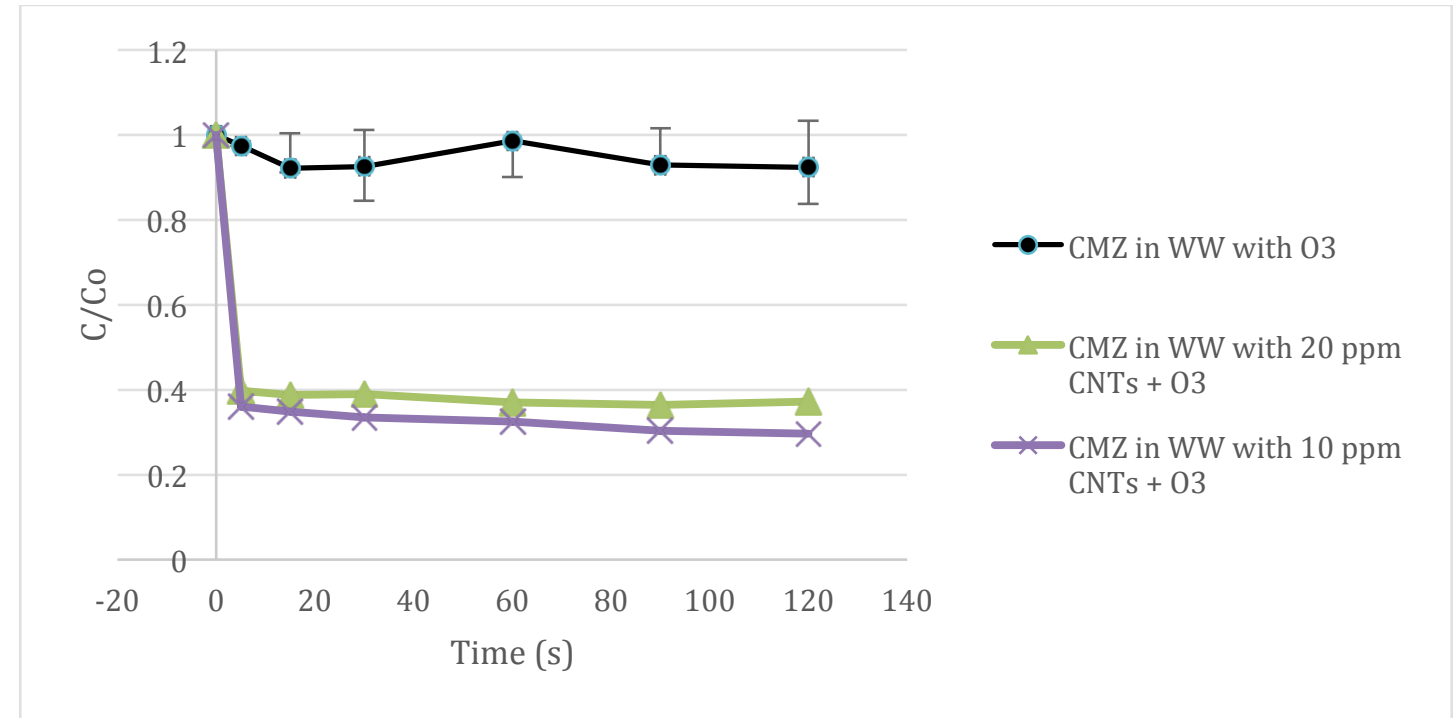

Figure C: Degradation of CMZ in the wastewater media tests with comparison to control. 